\title{
ENTRE LA MOVILIZACIÓN Y EL ESTADO. LAS POLÍTICAS PARTICIPATIVAS DE JUVENTUD EN LA ARGENTINA ACTUAL
}

\author{
MELINA VÁSQUEZ
}

\begin{abstract}
RESUMEN
El artículo realiza un abordaje sociohistórico sobre la dimensión participativa en el impulso de regulaciones estatales en Argentina. Se toma como punto de partida la década del 80 , momento de creación de los organismos nacionales de juventud, y se llega hasta el presente explorando las condiciones sociológicas que hacen inteligible la revitalización de la cuestión participativa en el impulso de políticas públicas juveniles. Asimismo, se despliega y analiza un amplio abanico de sentidos acerca de la participación que confluyen en implementación de políticas públicas de juventud, recuperando el punto de vista de diversos actores y grupos involucrados con su diseño e implementación. El trabajo propone reflexionar en torno a algunas paradojas propias del contexto argentino actual por medio del análisis situado de las vinculaciones entre movilización sociopolítica de las juventudes, Estado y políticas públicas.
\end{abstract}

PALABRAS ClAVE: ACTIVISMO, ESTADO, JUVENTUDES

* Licenciada en Sociología, Magíster en Investigación en Ciencias Sociales y Doctora en Ciencias Sociales por la Universidad de Buenos Aires (UBA). Postdoctora en Investigación en Ciencias Sociales, Niñez y Juventud (CLACSO/Universidad de Manizales/PUC San Pablo). Docente de la UBA e investigadora del Instituto de Investigaciones Gino Germani (UBA) y del Consejo Nacional de Investigaciones Científicas y Técnicas. E-Mail: mvazquez@sociales.uba.ar.

Trabajo de investigación realizado en el marco del proyecto IIGG-UBA/ CONICET. 


\title{
ENTRE A MOBILIZAÇÃO E O ESTADO. AS POLÍTICAS PARTICIPATIVAS DE JUVENTUDE NA ARGENTINA ATUAL
}

\begin{abstract}
RESUMO
O artigo realiza uma abordagem sóciohistórica da dimensão participativa no impulso de regulamentações estatais na Argentina. O ponto de partida é a década de 1980, momento da criação dos organismos nacionais de juventude, chegando até o presente explorando as condições sociológicas que tornam inteligível a revitalização da questão participativa no impulso de políticas públicas juvenis. Da mesma forma, é analisado um amplo espectro de sentidos sobre a participação que confluem na implementação de políticas públicas de juventude, recuperando o ponto de vista de diversos atores e grupos envolvidos em sua planificação e implementação. $O$ trabalho propõe refletir sobre alguns paradoxos próprios do contexto argentino atual através da análise situada das ligações entre mobilização sociopolítica das juventudes, Estado e políticas públicas.
\end{abstract}

PALAVRAS CHAVE: ATIVISMO, ESTADO, JUVENTUDES

\section{BETWEEN THE MOBILIZATION AND THE STATE: PARTICIPATIVE POLICIES OF YOUTH IN CONTEMPORARY ARGENTINA}

\begin{abstract}
Based on a sociohistorical perspective, the present article tackles the participative dimension driving state regulations in Argentina, from the 80s and the creation of youth national organizations, to the present days and the exploration of the sociological conditions ensuring a revitalized participation in driving youth public policies. Likewise, a wide spectrum of aspects concerning participation leading to the application of public youth policies are analyzed, taking into account the perspectives of the different actors and groups involved in its design and implementation. The document thus, is an invitation to reflect on characteristic paradoxes of the current Argentinian context, by means of an analysis of the links between sociopolitical mobilization of youths, State and public policies.
\end{abstract}

KEY WORDS: ACTIVISM, STATE, YOUTHS 


\section{POLÍtICAS PARTICIPATIVAS ${ }^{l}$ Y JUVENTUD: ENFOQUES, LECTURAS Y ÁMBITO DE VACANCIA}

EL PRESENTE TRABAJO BUSCA analizar las políticas participativas de juventud en la Argentina contemporánea. Para ello, se analiza el modo en que se configuran los sentidos y prácticas en torno a la idea de participación, la cual es vista centralmente desde el impulso de las políticas públicas llevadas adelante por el organismo sectorial de juventud con mayor jerarquía a nivel nacional: Dirección Nacional de Juventud (DINAJU), hasta el año 2014, y la Subsecretaría de Juventud (SSJ), dependientes del Ministerio de Desarrollo Social de la Nación.

El trabajo se interesa, por un lado, por una aproximación sociohistórica a la luz de la cual se muestra que la dimensión participativa en las políticas de juventud, que constituye una marca de origen de los organismos sectoriales de juventud a nivel nacional en la década del 80 en Argentina. En un contexto internacional en el que las juventudes comienzan a formar parte de la agenda política e institucional, y de un contexto nacional de reconstrucción de las instituciones democráticas luego de la última dictadura militar (1976-1983), la participación aparece como algo a promover e impulsar desde las políticas públicas destinadas a las juventudes.

El trabajo explora las propiedades distintivas de dicho contexto pero, centralmente, el escenario que se abre hacia fines del gobierno de Néstor Kirchner (2003-2007) y, más específicamente, durante los gobiernos de Cristina Fernández de Kirchner (2007-2011 y 2011-2015); en el cual se reconoce, por un lado, una reconfiguración de la movilización juvenil y, por otro, la juventud pasa a ser construida como un principio de distinción y de reconocimiento dentro del campo político (Vázquez, 2013). En otros términos, la cuestión participativa reaparece y adquiere nuevos sentidos. Así, el abordaje de las políticas participativas de juventud permite explorar una de las maneras de producir las juventudes a nivel estatal como también de acceder al análisis de las transformaciones en las maneras de tramitar los compromisos militantes. El análisis de los sentidos que dan diferentes grupos y actores a la idea de participar en el marco de la implementación de las mencionadas

1 Se hará uso de las itálicas para indicar términos o expresiones utilizados por actores e instituciones, las comillas serán utilizadas para introducir términos académicos y para citar discurso indirecto, indicando en ambos casos la fuente correspondiente. 
políticas, permite entender cómo y por qué los dispositivos participativos pueden ser leídos como puntapié, como modo de extensión o como consagración de formas de militancia. Así como también que el Estado y, más concretamente, el trabajo en determinadas áreas estatales vinculadas con el impulso de políticas públicas participativas de juventud es integrado al repertorio de acciones militantes de los grupos juveniles oficialistas, esto es, que militan en apoyo de las gestiones de gobierno de Cristina Fernández. Parte de la militancia se define en el trabajo en el Estado, como también en la reivindicación militante de gestiones consideradas exitosas, sobre todo en materia de políticas públicas. Podremos ver así, cómo tanto los organismos de juventud como las políticas públicas que de estos dependen tienden a ser modificados por prácticas participativas y militantes.

A la luz de las diferentes cuestiones mencionadas, se abordan las condiciones sociopolíticas e históricas por las cuales el impulso de la participación desde un conjunto de políticas públicas de juventud encuentra importantísimos puntos de contacto y conexión con el desarrollo de un tipo específico de militancia juvenil.

Ahora bien, los sentidos que se construyen acerca de la participación son múltiples y no se agotan en la anterior descripción. Trabajos realizados en diferentes países de América Latina sobre políticas públicas participativas — en general, no solamente de juventud - han mostrado la relación que guardan aquéllas con una serie de sugerencias y lineamientos elaborados desde organismos internacionales, en los cuales la promoción de la participación aparece entrelazada con un conjunto de recomendaciones para el impulso de políticas públicas y regulaciones socioestatales (Inzusa Vera y Olvera, 2006; Dagnino, 2006; Landau, et al., 2006; Borzese et al., 2006 y Aguilar et al., 2006). De acuerdo con estos trabajos, trasformaciones de los organismos internacionales de crédito — como el Banco Mundial- propiciaron que las reformas o estrategias de ajuste, características de la década del 90 dieran lugar al impulso de las llamadas estrategias de desarro$l l o$, en las cuales la participación es interpretada como elemento central para solucionar aquello que los propios organismos califican como los problemas centrales de América Latina: la pobreza y la debilidad institucional. ${ }^{2}$ La literatura ha mostrado que los lineamientos de polí-

2 En la medida en que la pobreza es interpretada como fruto del mal desempeño de las autoridades y funcionarios estatales, la participación, el empoderamiento y el monitoreo cívico pasan a ser leídos como límite a 
tica pública elaborados desde diferentes organismos internacionales se observan en el diseño de políticas participativas a nivel nacional (Aguilar et al., 2006) y resultan concomitantes tanto con la descentralización de las acciones estatales y la promoción de nuevas formas de gobierno no estatalizadas (Borzese, et al., 2006:109) como también con la emergencia de formas de participación promovidas por el Estado (Landau, 2008).

Otros trabajos (Inzusa Vera y Olvera, 2006; Dagnino 2006), mostraron el carácter ambivalente que posee la emergencia de discursos y prácticas que promueven e impulsan una mayor participación en la vida pública, puesto que en estos confluyen términos y nociones que remiten tanto a un enfoque neoliberal - sustentado por organismos financieros internacionales, organizaciones no gubernamentales con funcionamiento a escala global, fundaciones internacionales-, como también un ideario democrático-participativo sostenido por algunos gobiernos latinoamericanos. Esto nos lleva a tratar una cuestión también presente en diferentes trabajos realizados sobre América Latina, en los que la dimensión participativa es asociada a la construcción de modelos de democracia participativa, que emergen como respuesta al malestar con la democracia representativa liberal (Restrepo, 1997; Inzusa Vera y Olvera, 2006). Esta cuestión ha sido objeto de reflexiones específicas para el caso Argentino, sobre todo en el análisis de la emergencia y proliferación de políticas públicas participativas con posterioridad a la profunda crisis de representación política que tiene lugar en diciembre el año 2001 al calor de un ciclo de protestas cuya demanda principal fue «que se vayan todos, que no quede ni uno solo». ${ }^{3}$ Las masivas protestas, las consignas enarboladas y las experiencias organizativas que surgen en esa crisis tuvieron un profundo impacto no solo en su momento sino además en el intento de reconstrucción de la normalidad (Svampa, 2011) que tiene lugar tiempo después, más concretamente, a partir de la nueva gestión de gobierno en el año

la corrupción. En síntesis, y de modo esquemático. A mayor participación ciudadana menor será la pobreza. Asimismo, la participación es leída como una forma monitoreo cívico que hace viable la transparencia y el accountability, favoreciendo así la reconstrucción de la confianza en la administración pública y en las instituciones.

3 Como efecto de la enorme conflictividad social, no solo se produce la renuncia el entonces Presidente de la Nación, Fernando De la Rúa (1999-2001) sino además de los cuatro presidentes provisionales que lo suceden entre diciembre de 2001 y enero de 2002. 
2003, con Néstor Kirchner. Tal es así que se observa, al menos inicialmente, un reconocimiento institucional de algunos de los actores y las demandas sostenidas (Rofman, 2007), la construcción de un tipo de liderazgo que intenta legitimarse en la movilización (Pérez y Natalucci, 2012) y, también, el impulso de políticas públicas que se hacen eco de las transformaciones en los modos de representación y participación política, en los cuales la llamada «legitimidad de proximidad» cobra centralidad (Annunziata, 2013).

La hipótesis que sustenta el trabajo es que el principio participativo en la implementación de políticas públicas puede leerse en relación con tres procesos que, a priori, no parecen guardar relación pero cuyos vínculos emergen a partir del análisis situado. En primer término, el desplazamiento de la dimensión participativa de las políticas públicas, nutrido del ideario de las reformas de segunda generación, hacia las políticas de juventud. En segundo término, la confluencia entre aquellos postulados neoliberales que tienden a exaltar los mecanismos participativos como prácticas que se derivan de los procesos de descentralización y reforma del Estado y que permiten, desde el punto de vista de dichos organismos internacionales, incorporar un modelo multiactoral y participativo con un proceso de movilización y consagración militante de las juventudes que encuentra condiciones de posibilidad en relación con la gestión de políticas públicas de juventud. Finalmente, la centralidad que posee la cuestión participativa al interior de los organismos de juventud en Argentina - desde sus orígenes en la década del 80 y conforme a los postulados de los organismos internacionales de juventud, es definida como una suerte de «deber ser» en la gestión estatal de las juventudesencuentra específicas condiciones de posibilidad para recrearse en un nuevo sentido, en el contexto actual. Esto último no puede ser escindido de las particularidades que posee la dimensión participativa en la cultura política argentina.

La confluencia entre estos tres procesos involucrados con la promoción de la cuestión participativa en las políticas públicas no ha sido objeto de reflexión específica desde el campo de estudios de las juventudes. En efecto, al menos en el caso Argentino, los estudios sobre juventudes permanecen relativamente escindidos entre aquellos trabajos orientados a comprender las políticas públicas de juventud, por un lado, y los procesos de movilización y organización colectiva, por otro.

Por ello, para abordar los objetivos propuestos, el trabajo se nutre y busca establecer puentes entre diferentes campos de estudio con fuerte desarrollo en la literatura académica en Argentina pero cuyas 
relaciones - a diferencia de otros países de América Latina- no han sido suficientemente exploradas. Nos referimos, en primer lugar, a los trabajos sobre políticas públicas participativas, que exploran las condiciones de posibilidad para la emergencia de políticas públicas participativas pero no analizan las destinadas a las juventudes. En segundo lugar, a los estudios sobre juventudes y movilización política, que abordan los modos de participación y militancia juvenil, las acciones colectivas y los ciclos de movilización política pero no siempre se interrogan por las vinculaciones e impactos que esto posee sobre las instituciones políticas y las políticas públicas. Finalmente, a los trabajos sobre políticas públicas de juventud, en los cuales la indagación sobre las políticas participativas ha sido marginal.

Los elementos y perspectivas descriptos buscan dar cuenta de la heterogeneidad de sentidos en torno a la dimensión participativa, cuya fisonomía es específica y distintiva en un contexto sociopolítico en el cual la categoría joven o juventud se construye como uno de los principales términos de la movilización política (Vázquez, 2013). Al mismo tiempo, nos permite advertir sobre algunas paradojas - que se abren a la luz del caso estudiado - entre la participación y el Estado. En otros términos, es de interés para este trabajo explorar en qué condiciones y por qué razones sociológicas la participación y la movilización política juvenil pasan a ser tema de agenda política y estatal, los modos en que estas relaciones se tramitan y las disputas que esto produce. A la luz de estas cuestiones se podrán advertir no solo distintos significados de la participación sino, además, el modo en que se tramitan disputas por el sentido legítimo de la juventud militante.

\section{HACIA LA CONSTRUCCIÓN DE UNA MAPA: LAS POLÍTICAS PARTICIPATIVAS EN PERSPECTIVA}

Las políticas públicas de juventud que incluyen el trabajo con la cuestión participativa no han sido - con contadas excepciones - objeto de atención y de análisis en los trabajos académicos en Argentina. Cabe destacar, en este sentido, el valioso aporte que ofrecen los trabajos de Krauskopf (1998; 2005) y de Balardini (1999; 2004), quienes se han preocupado por detectar y definir los rasgos más sobresalientes de estas políticas. ${ }^{4}$ Dichos trabajos muestran, de modo general, cómo la partici-

4 Los trabajos de Balardini son especialmente importantes porque, además de estos rasgos comunes, se han centrado en el estudio de las 
pación de las juventudes comienza a ser objeto de las regulaciones socioestatales desde las cuales se postulan diferentes sentidos y significados acerca de los derechos (a participar) que ponen en juego el reconocimiento de las juventudes como actores en el ejercicio de sus derechos ciudadanos. La configuración que destaca la dimensión participativa, como sostienen los autores, expresa un cambio de paradigma en el que se modifica el modo tratar y trabajar con las juventudes.

De acuerdo con el interés por tener un panorama general de las políticas públicas de juventud $\mathrm{y}$, más específicamente, ponderar el peso relativo y las propiedades específicas de las llamadas políticas participativas - qué son, cómo se implementan, qué tipo de acciones llevan adelante - en la Argentina actual, se realizó un relevamiento de las políticas públicas implementadas por organismos estatales nacionales, destinadas específicamente a la juventud y/o en las cuales se incluye el trabajo con población en la franja etaria de 15 a 30 años, definida desde el propio Estado como juvenil. ${ }^{5}$ El mismo incluye un total de 156 políticas, entre las que se identifican Programas, Planes y líneas de acción nacionales implementadas entre los años 2010 y $2014,{ }^{6}$ cuyo listado puede consultarse en el anexo.

configuraciones específicas de las producciones participativas en $\mathrm{Ar}$ gentina, vistas tanto a la luz de las políticas públicas, como de la gestión de una experiencia muy singular - sobre la que haremos alusión más adelante - como es el Gabinete Joven de la Provincia de Santa Fe.

5 Con el fin de evitar una definición normativa $-\mathrm{y}$ previa a la realización del trabajo - respecto de qué es una política de juventud, se buscó un principio de recorte que permitiera ilustrar el modo en que desde el propio espacio estatal se definen las regulaciones destinadas a las juventudes. Por ello se trabajó, por un lado, con todas aquellas políticas, líneas o acciones que definen explícitamente a la/s juventud/es como población objetivo (el $60 \%$ de las políticas se define en este sentido). Por otro lado, se incluyen aquellas políticas implementadas para la franja etaria que el propio estado define como juvenil, esto es, entre los 15 y los 29 años de edad. Políticas que representan el $40 \%$ del relevamiento (Vázquez, 2015).

6 Es pertinente tomar en cuenta que en el relevamiento realizado se reúnen acciones muy disímiles en cuanto a tiempo de duración, alcance, cantidad de destinatarios, impacto y disposición presupuestaria. De modo que entre las 156 políticas relevadas podemos encontrar políticas definidas en términos programáticos, cuya intervención es regular, sostenida en el tiempo, con un importante presupuesto y que suponen una planificación más a largo plazo — como por ejemplo el Programa Jóve- 
Las políticas fueron organizadas por medio de una tipología, elaborada contemplando los principales lineamientos, orientaciones y objetivos que propone cada una de las acciones, y en función de la cual se pueden identificar ocho tipos de políticas de juventud:

a) Políticas de inclusión social, orientadas a trabajar sobre aquello que se define como garantía, protección y/o defensa de derechos ciudadanos;

b) Políticas de inclusión y terminalidad educativa, en las cuales se apunta a promover el derecho a la educación y a la finalización de los ciclos educativos en sus distintos niveles;

c) Políticas de preventivas, que despliegan acciones a partir de situaciones definidas como problemáticas o riesgosas —en términos reales o potenciales - para los jóvenes, entre las que se encuentran las políticas punitivas y de control social;

d) Políticas de inclusión en el mercado laboral, que buscan impulsar o promover el acceso y la incorporación juvenil al mercado laboral formal, así como también mejorar y/o proteger su inserción en aquél;

e) Políticas de apoyo al desarrollo económico y a los emprendimientos productivos;

f) Políticas de promoción del desarrollo cultural de los jóvenes, vinculadas con la promoción del acceso, uso y consumo de bienes culturales por medio de actividades recreativas;

g) Políticas de formación cívica, que tienen entre sus principales objetivos generar procesos de aprendizaje y formación de las juventudes vinculados con el ejercicio de los derechos cívicos. ${ }^{7}$

nes Más y Mejor Trabajo o el PROGRESAR - , frente a otras que no se definen en términos programáticos, se basan en la realización de acciones muy específicas (como concursos, encuentros, jornadas y talleres) y de corta duración (entre uno y tres días), sin presupuesto fijo ni continuidad en el tiempo, como por ejemplo los Talleres de Comunicación y de Derecho Sexual, las Jornadas «Derechos de Personas con Discapacidad» y los concursos de literatura «Cuentos Cortos. La Historia la ganan los que escriben» o «Argentina Comparte Historias de Compromiso», entre otros. Pese a que esto puede ser visto como una debilidad, la realización del relevamiento -asumiendo sus limitaciones- permite sistematizar y construir un mapa general de las acciones estatales destinadas a las juventudes en el contexto actual.

7 Se identifican iniciativas por las que se apunta a transmitir y ponderar la importancia de los derechos y un conjunto de elementos definidos como valores democráticos al interior de los espacios educativos, también hay 
h) Políticas participativas, que buscan promover e impulsar la participación juvenil como objetivo central de sus acciones. Siguiendo su definición normativa, son políticas que tienen como fin acompañar, estimular o impulsar la organización de las juventudes.

Independientemente de la cantidad de orientaciones en las políticas públicas de juventudes, resulta interesante advertir el peso específico de cada uno de ellas, tal como se puede reconocer en el cuadro 1 a continuación.

CUADRO 1: POLÍTICAS PÚBLICAS DE JUVENTUD SEGÚN TIPO.

PERÍODO 2010-2014. DATOS EN PORCENTAJES

\begin{tabular}{|l|c|c|}
\hline Tipo de Política Pública & Porcentajes & Absolutos \\
\hline $\begin{array}{l}\text { Inclusión social y acceso de } \\
\text { derechos }\end{array}$ & $21 \%$ & 32 \\
\hline Inclusión y terminalidad educativa & $19 \%$ & 30 \\
\hline Preventivas & $10 \%$ & 16 \\
\hline $\begin{array}{l}\text { Inclusión en el mercado } \\
\text { laboral formal }\end{array}$ & $9 \%$ & 14 \\
\hline $\begin{array}{l}\text { Apoyo al desarrollo económico y } \\
\text { emprendimientos productivos }\end{array}$ & $6 \%$ & 10 \\
\hline Culturales & $8 \%$ & 12 \\
\hline Formación cívica & $4 \%$ & 35 \\
\hline Participativas & $23 \%$ & 156 \\
\hline Total & $100 \%$ & 75 \\
\hline
\end{tabular}

Fuente: elaboración propia con base en relevamiento de políticas de juventud.

Las políticas participativas representan casi una cuarta parte de las políticas de juventud relevadas, seguidas por las de Inclusión social y acceso a derechos $(21 \%)$ y por las de Inclusión y terminalidad educativa $(19 \%)$.

Ahora bien, entre las primeras, se pueden reconocer diferentes orientaciones. En algunas políticas, el impulso de la participación es postulado en relación con ámbitos sociales específicos, como se observa en los Foros por la Democratización Universitaria (dependiente

otras que proponen fomentar instancias de reflexión y análisis a partir de hechos y temas definidos como relevantes dentro de la historia política argentina. En estas políticas las juventudes son construidas en relación con categorías etarias y de acuerdo con la condición estudiantil de sus destinatarios, sobre todo de nivel medio. 
la SSNJ) y en el Programa Nacional de Educación Solidaria (dependiente del Ministerio de Educación), en los cuales el foco del trabajo está puesto en el ámbito educativo. Así, estas acciones buscan promover la participación — según los ejemplos escogidos - en la escuela. En otros casos, la participación es definida como una experiencia y como un valor a difundir o en el que socializar a los jóvenes. En estas políticas también se da valor al ámbito educativo pero más bien por el hecho de que es caracterizado como el ámbito por excelencia para promover la formación ciudadana y el ejercicio de derechos políticos. Es decir, que el espacio educativo no es visto como escenario de la participación propiamente dicha sino más bien como un espacio en el que se enseña y se aprende a participar. En este sentido, se pueden destacar diferentes acciones encaminadas a impulsar la creación de estrategias organizativas entre los y las jóvenes, como por ejemplo Mutuales del Bicentenario (dependiente del Consejo Federal de Juventud), el Programa Parlamento Juvenil del Mercosur (dependiente del Ministerio de Educación), entre otras a destacar.

La revisión de los diferentes tipos de políticas destinadas a las juventudes permite advertir que la participación no es solamente un fin que persiguen muchas de las políticas de juventud sino que además, es puesto como un medio para poder facilitar la consecución de otros fines. En algunos casos, la participación se configura como una forma de inserción territorial, local o comunitaria de las políticas, como se observa en el Programa Empleo Comunitario (dependiente del Ministerio de Trabajo, Empleo y Seguridad Social). En otros casos, la participación se define como un «medio», en cuanto es asociado a una forma de prevención. Esta, a su vez, reconoce diferentes sentidos, que van desde la Prevención del Abandono Escolar (nombre que lleva una política dependiente del Ministerio de Educación) hasta la prevención del delito, como es el caso de los Programas Nuestro Lugar y Acá la Palabra (Ministerio de Desarrollo Social) y del Programa Comunidades Vulnerables (Ministerio de Justicia de la Nación). En otros casos, el foco está puesto en la prevención del consumo de drogas y alcohol, como en el Programa de Prevención y Participación Juvenil (Secretaría de Programación para la Prevención de la Drogadicción y la Lucha contra el Narcotráfico, Presidencia de la Nación). En estas políticas, la participación juvenil se configura como elemento transversal a las políticas públicas impulsadas desde diferentes áreas estatales que, pese a reconocer diversos objetivos, encuentran en aquélla un medio o recurso que favorece su implementación. 
Si sumamos las políticas que persiguen como fin la organización y/o participación juvenil con aquellas otras en las cuales lo participativo se convierte en una herramienta o un medio para cumplir otros objetivos (no necesariamente participativos), el porcentaje asciende del 23\% al 34\%. Lo interesante es observar el amplio abanico de sentidos que se despliegan en torno a idea de participar: como medio para aplicar políticas con otros objetivos; como resultado de la adquisición de un saber; como objetivo a cumplir durante la implementación de las políticas (en encuentros, talleres, etc.) y como una práctica concreta por medio de la cual se ensayan maneras de organizarse entre los y las jóvenes.

Si observamos de qué organismos estatales dependen las políticas destinadas a las juventudes, llama la atención advertir la importancia del Ministerio de Desarrollo Social, que impulsa el 28\% de las políticas de juventud. Su centralidad se desprende, en parte, del hecho de que bajo su órbita funcionan los dos espacios sectoriales de juventud de mayor importancia a nivel nacional: la Subsecretaría Nacional de Juventud y el Consejo Federal de Juventud. Los cuales impulsan casi el 60\% del total de los programas, iniciativas y líneas de acción del Ministerio, distribuyéndose los restantes entre la Secretaría Nacional de Niñez, Adolescencia y Familia (11\%), la Secretaria de Deportes (11\%) y la Secretaria de Políticas Sociales y Desarrollo Humano (5\%).

Al Ministerio de Desarrollo Social le sigue el de Educación, que impulsa el 21\% de las políticas públicas de juventud. El 51\% restante se distribuye entre 16 Ministerios y organismos, que implementan entre el $1 \%$ y el $7 \%$ de las políticas juveniles respectivamente. Si observamos la distribución de las políticas participativas de juventud, la importancia relativa de ambos Ministerios se mantiene, dado que el primero impulsa $63 \%$ y el segundo el $14 \%$, seguido por la Jefatura de Gabinete de Ministros de la Nación, con el 11\%.

La centralidad de los organismos de juventud en el diseño e implementación de políticas públicas de juventud se presenta de modo ambivalente puesto que, aun cuando retienen la mayor cantidad de acciones, si observamos con detenimiento cuáles son las regulaciones impulsadas podremos notar, por un lado, que los organismos de juventud no impulsan programas de juventud propiamente dichos, sino más bien líneas de acción con una limitada continuidad en el tiempo y que carecen de presupuesto propio. Por otro lado, y en relación con lo anterior, los programas y acciones con mayor impacto en materia de juventud —como podría ser, por ejemplo, la Asignación Universal por 
Hijo (AUH) — ${ }^{8}$ son impulsados por otras áreas y Ministerios, desde los cuales las juventudes son tratadas centralmente como grupos de edad, es decir que no reconocen un tratamiento específico.

\section{LAS POLÍTICAS PARTICIPATIVAS DESDE UNA MIRADA GENEALÓGICA: ENTRE LO NACIONAL Y LO INTERNACIONAL}

En el apartado anterior se realizó una caracterización general de las políticas de juventud en el presente, mostrando el peso relativo de las acciones impulsadas, los organismos de los que dependen y los grandes lineamientos que siguen. Uno de los elementos que se deja entrever es la importancia relativa de las políticas participativas y su relación con los organismos de juventud. Para poder poner esto en contexto e identificar aquellos aspectos que parecen mostrar relaciones de continuidad, como también aquellos otros que se revelan novedosos, en este apartado se realiza una reconstrucción de los orígenes de los organismos y las políticas de juventud en Argentina, atendiendo al modo en que aparece en esta reconstrucción genealógica la cuestión participativa.

Un primer elemento a contemplar es la proclamación del Año Internacional de la Juventud (AIJ) por parte de las Naciones Unidas en 1985, que representa un hito fundacional en las instituciones y en el impulso de políticas públicas de juventud en Argentina puesto que fueron creadas a partir de las de comisiones preparatorias del AIJ. ${ }^{9} \mathrm{De}$

8 Transferencia de ingresos mensual por cada hijo menor de 18 años a padres/padres o tutores que estén desocupados, sean trabajadores del mercado informal o cuyos ingresos son menores al salario vital y móvil. La percepción del pago está condicionada a la escolarización de los/as y al cumplimiento de controles de salir de los menores. El total de beneficiarios de esta política asciende a 3.500 .000 y representa una inversión social de 55 millones de pesos argentinos. Esta política depende y está financiada por la Administración Nacional de la Seguridad Social (ANSES).

9 La ausencia de un trabajo específico en materia de juventud a nivel estatal hasta la década del 80 se reconoce en diferentes informes realizados en la época en los que se destaca, por ejemplo, la importancia de organizar diagnósticos y producciones académicas a la luz de los cuales se pueda problematizar el trabajo con las juventudes. En efecto, los primeros trabajos de consultoría son fundacionales del campo de estudios académicos sobre juventudes, así como también las experiencias impul- 
acuerdo con la literatura (Balardini y Hermo, 2007; Núñez, 2004), hasta entonces, no se reconoce un desarrollo visible y sostenido de políticas públicas de juventud. ${ }^{10}$

La proclamación del AIJ da lugar a la formación de áreas de juventud a nivel provincial y favorece el impulso - en 1986- de un área de Juventud en la Secretaría de Desarrollo Humano y Familia, antecedente inmediato de la formación de la Subsecretaría de la Juventud a nivel nacional en 1987. En esta Subsecretaría funciona la Comisión Interministerial de la Juventud, que constituye el primer intento de articulación y coordinación de las políticas dirigidas a los jóvenes entre diferentes áreas del Estado nacional.

Vemos así que la creación de los organismos de juventud tiene lugar en respuesta a la construcción de un tema de la agenda gubernamental instalado desde fuera, más precisamente por las Naciones Unidas, como tema de relevancia. Ahora bien, tal como lo atestiguan trabajos realizados en otras latitudes - como en el caso de Brasil (Wendel Abramo, 2004) - , la mera construcción de una agenda internacional sobre juventudes no resulta suficiente para explicar cómo y por qué se crean programas y organismos de juventud. Por eso, resulta vital analizar el contexto sociopolítico local, esto es, el escenario post dictatorial de la Argentina entre principios y mediados de la década del 80. Reponer dicho contexto permite echar luz acerca de cómo y

sadas desde la SSJ en relación con instituciones académicas como FLACSO y en torno a actividades de formación realizadas con el Instituto de Juventud de España.

10 Hay algunas excepciones si observamos, por ejemplo, el desarrollo de actividades deportivas y de movilización de masas canalizadas por la Unión de Estudiantes Secundarios durante el primer gobierno de Juan Domingo Perón (1945-1955) (Balardini y Herno, 2007). Asimismo, durante la última dictadura militar (1976-1983), se combina la estrategia represiva hacia las juventudes con la consagración de un modelo de juventud nutrido de virtudes militares por parte de la propaganda oficial. Esto se reconoce, a modo ilustrativo, en la construcción de los jóvenes combatientes en la Guerra de Malvinas que tuvo lugar en 1982 (Lorenz, 2006), así como también — tal como lo atestigua el trabajo de Gonzáles (2014) sobre la Provincia de Córdoba - en el impulso de políticas culturales que recuperan el imaginario bélico, autoritario y militarista. Así, la sana recreación de los jóvenes en torno a prácticas culturales aparece como una forma de salvación de las almas frente a los males que los asechan, a saber: «el terrorismo, las drogas, la pornografía y los juegos electrónicos» (Op. cit., 74). 
por qué el centro de las acciones estatales en materia de juventud estará puesto en la reconstrucción del valor de lo público y de las instituciones democráticas. Según Alejandro Tullio, Subsecretario Nacional de Juventud durante el gobierno de Raúl Alfonsín (1983-1989), «hablar de política de juventud era crear áreas desde el gobierno, desde el Estado, para atender los casos juveniles» (Tullio, 2013). La apuesta por trabajar con la dimensión institucional propiamente dicha llevó - como sostiene el entonces funcionario- a que la articulación con las juventudes movilizadas no fuera un tema prioritario de la gestión.

Desde la creación del organismo nacional de juventud en 1987 en el marco del gobierno constitucional de Raúl Alfonsín y el año 1989, cuando termina su mandato y asume Carlos Menem como primer mandatario, perteneciente al Partido Justicialista, el foco principal de la SSJ tiene que ver con apuntalar la conformación del organismo. De ahí la importancia que se da a la formación de técnicos y a obtener reconocimiento por parte de la administración pública. En esta etapa inicial adquiere importancia el contacto con otros modelos considerados exitosos, de los que se busca extraer aprendizajes y experiencias (Balardini, 1999). Se puede hacer mención, por un lado, al Instituto de Juventud (creado en 1985, a partir de las celebraciones del AIJ) de España ${ }^{11} y$, por otro, al caso mexicano, el cual es conocido a partir del contacto que intelectuales y profesionales exiliados de la Argentina antes y durante la última dictadura militar desarrollan con el Consejo Nacional de Recursos para la Atención de la Juventud (CREA), ${ }^{12}$ orientado a la promoción de la articulación entre las instituciones estatales y el campo académico como uno de los ejes centrales de las políticas de juventud.

Como lo atestiguan tanto documentos de la época como testimonios de actores vinculados con la etapa fundacional de la Subsecretaría, hacia fines de la década del 80 se reconoce una marcada presencia

11 La experiencia española se configura como una suerte de modelo a seguir en Argentina, a tal punto que la Subsecretaría de juventud replica su estructura administrativa y la forma de abordar la cuestión juvenil en articulación con las provincias y los municipios, como también el enfoque de las políticas públicas juveniles.

12 El modelo de gestión del CREA surge en 1977 como una vía institucional que busca dar respuesta a un clima de época marcado por las movilizaciones y manifestaciones juveniles en el espacio público, así como por el despliegue por parte del gobierno de estrategias de control social tendientes a reprimir, contener y limitar estas acciones colectivas. 
de la retórica participativa, la cual se extrae centralmente de los contactos internacionales en la etapa inicial de la SSJ. A título ilustrativo, se puede citar el documento «Promoción de la participación de la juventud argentina en el desarrollo sociocultural» (1987), elaborado por Ernesto Rodríguez —en calidad de consultor - para UNESCO. En el mismo se deja ver, por un lado, la importancia de organismos internacionales de juventud en la constitución de los organismos sectoriales de juventud a nivel nacional, como también porque el modo en que se incorporarán los modelos participativos. La cuestión participativa, es definida, por un lado, como un elemento central para la formulación de políticas de juventud. Por otro lado, la descripción de la dimensión participativa es anclada y entrelazada con rasgos del particular escenario argentino, destacando la importancia de un conjunto de aspectos que cobran valor en clave comparativa con el pasado dictatorial reciente: «fomentar la libre expresión y la participación protagónica de los jóvenes», el «compromiso de la juventud con la vida social, económica, política y cultural», y con «fomentar ideales que incentiven en ellos la solidaridad, el respeto por la justicia, la libertad, la paz, la defensa de las instituciones democráticas, la promoción de los derechos humanos».

Asimismo, participar es asociado con un repertorio de acciones específicas: a) la vinculación de las juventudes en el diseño de políticas públicas, b) con que las juventudes «participen del gobierno y no que sea el área del gobierno que actúa para la juventud sin su concurso» y c) con promover la participación en grupos de diversa índole que van desde las Organizaciones no Gubernamentales hasta los partidos políticos, pasando por la iglesia y los sindicatos.

En síntesis, el uso del término participación en el marco de la implementación de las políticas públicas de juventud en la etapa de creación de los organismos sectoriales a nivel nacional reconoce un significado específico, situado en el período postdictatorial en Argentina y le imprime particularidades que la asocian con el valor de reconstruir los vínculos sociales e institucionales quebrados durante el gobierno de facto (Liguori, 2015).

Ahora bien, la cuestión participativa encuentra condiciones de finalización hacia 1989, cuando asume como primer mandatario Carlos Saúl Menem (1989-1995, 1995-1999). Como lo sugiere la reconstrucción histórica de las políticas públicas y los organismos de juventud que realiza Balardini (1999), en la década del 90 el anterior ímpetu por la promoción de la participación cede lugar ante dos grandes cuestiones en materia de política de juventud: el consumo de drogas y el em- 
pleo; ambas trabajadas en relación con una mirada de la juventud como problema. Además, el área institucional de juventud a nivel nacional va oscilando, en algunas etapas perdiendo rango y en otras recobrándolo, sin que ello signifique un crecimiento presupuestario ni tampoco el manejo de una asignación presupuestaria propia.

Hasta el año 2003, los organismos sectoriales de juventud siguen un itinerario inestable, desplazándose por diferentes distintos Ministerios (de Acción Social y Desarrollo Social, del Interior), con diferentes jerarquías y formas (Secretaría, Subsecretaría, Instituto, Dirección, etcétera), así como también sufren vaivenes y modificaciones a raíz de los sucesivos cambios de funcionarios y de gobiernos. Desde entonces, el organismo de juventud se mantiene al interior del Ministerio de Desarrollo Social. Hasta febrero de 2014 funciona como Dirección Nacional de Juventud (DINAJU) y, desde entonces, como Subsecretaría Nacional de juventud (SSNJ). Asimismo, en el año 2008 se formaliza el Consejo Federal de Juventud (CFJ), bajo la órbita de la DINAJU y actualmente de la SSNJ. Esta relativa estabilidad institucional estuvo, sin embargo, fuertemente permeada por cambios de autoridades, disputas y pujas internas; las cuales llevaron a que el organismo de juventud tuviera un rol secundario con respecto al trabajo con las juventudes, al punto que aquellas políticas con mayor impacto o más emblemáticas en relación con las juventudes en el contexto actual - como el Programa Jóvenes con Más y Mejor Trabajo o la Asignación Universal por Hijono dependen ni de los organismos sectoriales ni de los Ministerios de los que éstos dependen. Esta situación resulta paradojal dado que, frente al proceso de configuración de las juventudes como tema de agenda de las gestiones de gobierno kirchneristas (2003-2007, 2007-2011 y 2011-2015), los espacios institucionales de juventud no parecen haber corrido la misma suerte. Centralmente, se trata de un área sin presupuesto propio, en las cuales los cambios de autoridades - incluso dentro de una misma gestión de gobierno - provocan fuertes discontinuidades y pujas internas y cuyas líneas de acción no son definidas en términos programáticos.

Ahora bien, como se intenta fundamentar en los próximos dos apartados, en el presente se puede observar una revitalización de la cuestión participativa que también cobra propiedades específicas a la luz del contexto en el cual son impulsadas. La dimensión participativa en el seno de las mencionadas acciones y líneas reconoce una doble confluencia. Por un lado, aparece como una suerte de traducción de los principios políticamente correctos en la elaboración de diagnósticos y 
sugerencias realizados por organismos internacionales de juventud y; por otro, como una especie de resignificación militante del Estado, impulsada por parte de funcionarios, gestores y trabajadores vinculados con el diseño e impulso de políticas públicas participativas, en las cuales - como planteamos anteriormente- el sentido del término participación es recreado y puesto en relación de continuidad con la participación política y la militancia.

\section{SENTIDOS DE LA PARTICIPACIÓN: LECTURAS E INTERPRETACIONES DESDE LOS ORGANISMOS INTERNACIONALES DE JUVENTUD}

En el año 2005 se elabora la Convención Iberoamericana de Derechos de los Jóvenes de la Organización Iberoamericana de Juventud (OIJ) ${ }^{13}$ en el marco de una reunión entre los representantes de sus Estados miembros en la que se definen lineamientos comunes para el impulso de las políticas públicas en los países que la integran. El artículo 21 de la Convención se centra exclusivamente en la participación juvenil y se define la importancia de que los Estados miembros garanticen el derecho a la participación política, a «inscribirse en agrupaciones políticas, elegir y ser elegidos»y, finalmente, que garanticen su activa vinculación con la «formulación de políticas y leyes referidas a la juventud, articulando los mecanismos adecuados para hacer efectivo el análisis y discusión de las iniciativas de los jóvenes, a través de sus organizaciones y asociaciones» (OIJ, 2005: 20)

Documentos posteriores, como el realizado por Licha (2006) para el Banco Interamericano de Desarrollo, también son ilustrativos del modo en que se va elaborando un diagnóstico sobre las juventudes y la formulación de propuestas específicas de política pública para hacer de los jóvenes ciudadanos activos. En esta misma dirección se puede hacer mención al documento elaborado por el Banco Mundial en el que Verner y Heinemann, (2008) destacan la centralidad de «atraer a los jóvenes para mejorar la gobernabilidad y la rendición de cuentas»

13 Organismo multigubernamental creado en 1992 con el propósito de promover la cooperación entre diferentes países Iberoamericanos en materia de juventud, del que forma parte la Argentina. La OIJ posee marcado reconocimiento internacional a nivel político y académico y — centralmente- es un organismo influyente en el impulso de políticas públicas de juventud para la región (Plesnicar, 2010). 
(Op. cit., 18). Entre las sugerencias formuladas para promover la participación juvenil se menciona: la creación de redes, la aproximación de los jóvenes al Estado, y del Estado a ellos, e incentivar la participación local. Asimismo, se pondera la participación juvenil en la formulación de políticas públicas para promover la creación de políticas «de abajo hacia arriba», y viceversa, así como «remover los obstáculos del Estado a la participación».

En este mismo documento del BM, Garcette, Gacitúa-Marió y Heinemann (2008) avanzan en la definición de la participación como algo a promover entre la juventud puesto que «los niveles bajos de participación se relacionan con la deserción escolar, el delito y la violencia» (Op. cit., 98). Asimismo, la participación política legítima es definida en relación con el ejercicio de un repertorio de acciones calificadas como ciudadanas, por lo cual se tiende a destacar que las acciones no institucionales o no tradicionales - como las impulsadas desde los nuevos movimientos sociales - comportan un límite para ello. En otras palabras, «Las limitaciones de canales y recursos para ejercer los derechos y las obligaciones de la ciudadanía dentro del ámbito político-institucional representan obstáculos que impiden a los jóvenes desarrollar su potencial como ciudadanos» (Op. cit., 100), es así como se descalifica la llamada movilización juvenil.

Los diferentes documentos mencionados muestran cómo se define la dimensión participativa desde los organismos internacionales de juventud. Ahora bien, de acuerdo con los propósitos de este artículo, se trata de documentos relevantes en la medida en que - de acuerdo con los resultados de un trabajo etnográfico desarrollado entre los años 2012 y 2014 en la DINAJU del Ministerio de Desarrollo Social de la Nación - son leídos, citados e incorporados en el diseño e implementación de las políticas públicas participativas de juventud a nivel nacional. Cuestión que se desarrolla en el apartado a continuación.

\section{RECONFIGURACIONES DE LA DIMENSIÓN PARTICIPATIVA A LA LUZ DE LOS ORGANISMOS SECTORIALES DE JUVENTUD A NIVEL NACIONAL}

Los documentos de los organismos internacionales ilustran, en consonancia con los hallazgos de otras investigaciones (Plesnicar, 2010), el modo en se hacen presentes las recomendaciones para el impulso de políticas participativas vistas desde el foco específico de las juventudes. Resta mostrar aún el modo en que dichas nociones se desplazan y 
se hacen presentes en las regulaciones socioestatales llevadas adelante desde las políticas de juventud en la Argentina contemporánea.

De acuerdo con los resultados del mencionado trabajo de campo con los organismos sectoriales de juventud nacional, son dos los modos en que los documentos citados y los puntos de vista esbozados circulan al interior de los organismos nacionales de juventud. Por un lado, es habitual la realización de actividades conjuntas, algunas de modo sostenido en el tiempo, entre organismos nacionales y organismos internacionales como la OIJ, Centro Latinoamericano sobre Juventud (CELAJU) ${ }^{14}$ Centro Latinoamericano de Economía Humana (CLAEH) ${ }^{15}$ International Development Research Center (IDRC/CDRI) ${ }^{16}$, UNESCO y, más concretamente, el Programa MOST dependiente de aquel. ${ }^{17}$ Algunas de estas relaciones datan de los orígenes mismos de los organismos de juventud a mediados de la década del 80 , tal como mencionamos con anterioridad. Por medio de estas interacciones se producen instancias de diálogo, de difusión de documentos y una suerte de socialización por parte de los funcionarios locales con los puntos de vista y recomendaciones elaborados desde aquellos organismos.

Por otro lado, los desplazamientos de las lecturas de los organismos internacionales de juventud en los nacionales, se observan en una serie documentos confeccionados desde los organismos de juventud a nivel nacional en los que aquellos otros documentos y nociones son

14 Organismo internacional no gubernamental creado en 1986 con el fin de ofrecer apoyo y asistencia técnica a gobiernos y organismos no gubernamentales que abordan temáticas de juventud. Trabaja mancomunadamente con la ONU y con otros organismos internacionales.

15 Organización sin fines de lucro creada en 1957 dedicada a la investigación científica interdisciplinaria y la elaboración de políticas públicas. Trabaja centralmente con organizaciones afines de América latina y el Caribe.

16 Organismo canadiense creado por el Parlamento en 1970 con el fin de colaborar con los países en desarrollo en sus principales problemáticas. Esta organización cuenta con apoyo financiero del Estado de Canadá y de otras organizaciones internacionales interesadas.

17 En efecto la Ministra de Desarrollo preside, desde el año 2009, el Consejo Intergubernamental del MOST, programa de Gestión de las Transformaciones Sociales de las Naciones Unidas para la Educación, la Ciencia y la Cultura (UNESCO). Uno de los principales objetivos del MOST es fomentar la creación de conocimiento para la toma de decisiones políticas. 
incorporadas. A modo ilustrativo, se pueden mencionar tres documentos elaborados por la Ministra de Desarrollo Social —editados como libros - en los que se vuelcan los pilares y principales lineamientos de las acciones desarrolladas y a desarrollar en materia social desde el referido Ministerio. Los mismos se titulan: «La Bisagra. Memoria, Verdad, Justicia y Organización Social» (2007); «Políticas Sociales del Bicentenario Un Modelo Nacional y Popular», tomos I y II (2010). Allí se definen nociones básicas con fuerte incidencia en los organismos de juventud (bajo la órbita de este Ministerio), entre las cuales aparece la dimensión participativa de las políticas públicas. No se trata de una mera reproducción de los términos o significados elaborados desde los organismos internacionales, sino más bien de una recuperación y resignificación de los mismos a la luz de elementos propios del contexto local.

En otros documentos con circulación entre autoridades y trabajadores de los organismos de juventud, también se observan caracterizaciones sobre el sentido de las políticas públicas de juventud desde un enfoque participativo. Estos son: «Políticas Sociales de Juventud. Aprendizajes y Desafíos. Perspectivas para la construcción de políticas participativas» (DINAJU, 2007) y «Lineamientos para una política integral de juventud en la Argentina de hoy» (DINAJU, 2011). El primero es elaborado a raíz de la implementación de un Programa específico pero se postula como un «aporte significativo para la reflexión acerca de las políticas sociales de juventud, desde un enfoque promocional y participativo que impulsa la construcción de dichas políticas CON y DESDE los/as jóvenes» (DINAJU, 2007:2), por medio del cual se busca colaborar con «la construcción de más y nuevos espacios de protagonismo para los/as jóvenes, reconociendo en estos actores la potencialidad transformadora para modificar la realidad social» (Ibídem). Allí se definen los rasgos sobresalientes de un modelo tradicional en el cual la juventud aparece como etapa de transición y es tratada como un problema, en el que se desarrollan políticas compensatorias y en el cual el impulso de regulaciones socioestatales es realizado para y por la juventud. Este modelo es contrapuesto con el enfoque de ciudadanía, en el cual los jóvenes aparecen como sujetos de derecho. Noción alrededor de la cual se menciona la centralidad de la «participación activa en la formación de políticas de juventudes» (Op. cit., 6). Se explicita, así, el pasaje de las políticas para y por la juventud hacia otras con y desde la juventud, en las cuáles participar tendría que ver con: a) la vinculación con los procesos de reflexión, de toma de deci- 
siones y de ejecución de las políticas públicas; b) la realización de acciones impulsadas autónomamente por colectivos y organizaciones de la sociedad civil y c) poner en ejercicio la ciudadanía juvenil. En síntesis, la participación es definida como:

... un derecho a partir del cual se construye la libertad pues permite decidir y tomar posiciones en el campo de la lucha y el poder: participar es apropiarse de los espacios públicos y construirlos. El ejercicio de participación como principio de ciudadanía política contribuye a la puesta en escena de actores, redes informales, organizaciones y cualquier otra forma de expresión donde converjan intereses comunes. Propiciar mecanismos para desarrollar y fortalecer la ciudadanía implica el desarrollo de nuevos dispositivos con el objeto de ampliar y recrear los espacios de participación (2007:13).

El segundo documento es realizado en 2011 por integrantes del Ministerio de Desarrollo Social de la Nación con la colaboración de UNESCO, más concretamente, bajo la coordinación de un miembro de Gestión de Proyectos Sociales, Educativos y Culturales (GESIP) quien trabaja como consultor en diversos organismos internacionales. ${ }^{18} \mathrm{Di}$ cho coordinador trabajó durante varios meses conjuntamente con ocho funcionarios del Ministerio de Desarrollo Social, bajo la supervisión de la entonces Directora Nacional de Juventud, conjuntamente con miembros de otras dependencias estatales, Organizaciones No Gubernamentales, agrupaciones políticas y académicos ${ }^{19}$.

El trabajo conjunto, se plasmó en un documento en el que se fijan un conjunto de criterios que pretenden guiar la implementación de políticas de juventud. Se toma como insumo un relevamiento de políticas públicas de juventud, se sistematizan consideraciones propositivas para orientar el impulso de una política integral de juventud y se definen los temas más relevantes a tratar, los actores que deben estar vinculados con la implementación de las mismas y en qué tipo de

18 Como la OEA, UNICEF, BID, OIT, PNUD. Asimismo, se trata de un colaborador del Ministerio de Desarrollo Social de la Nación desde el año 2004.

19 La figura elegida para la realización de este trabajo resulta interesante porque permite entender -concretamente- cómo bajo la figura del experto o del consultor se hace inteligible el modo en que se producen desplazamientos y la difusión de saberes, perspectivas, lineamientos y lecturas entre organismos gubernamentales, no gubernamentales e internacionales. 
entramado institucional. En el documento se detecta una suerte de desplazamiento semántico en el significado que se da al término participación. Pese a la presencia de algunos de los sentidos ya introducidos, por ejemplo la idea de que los jóvenes deben ser tratados como sujetos de derecho y no como meros destinatarios u objetos de la política pública, ese lenguaje políticamente correcto a nivel internacional para diseño de políticas participativas de juventud encuentra aquí especificidades vinculadas con la realidad sociopolítica nacional.

En un trabajo anterior (Vázquez, 2012), analizamos cómo parte del quehacer militante al interior de las agrupaciones políticas vinculado con la construcción de narrativas históricas en relación con las cuales los grupos se constituyen en cuanto tales. De ahí la centralidad que cobra la identificación de hitos fundacionales, clivajes y hechos destacados - como protestas, cambios de gestión de gobierno, masacres, etcétera - a la luz de los cuales se explicita la historia de esos grupos. Asimismo, en otro trabajo (Vázquez y Vommaro, 2012) mostramos cuáles son los hitos específicos que dan sentido a los colectivos juveniles afines al kirchnerismo. Resulta llamativo advertir en el mencionado documento un parecido de familia con las narrativas sostenidas por algunos colectivos de jóvenes militantes. Concretamente, se presenta una interpretación de la historia reciente a la luz de la cual, por un lado, se confiere y legitima la centralidad de la juventud en relación con los procesos de movilización política recientes y, por otro, se configura una particular manera de entender el Estado que es tributaria de los sectores juveniles movilizados que se reconocen afines al kirchnerismo. Reproducimos a continuación un fragmento que ilustra lo mencionado.

... es a partir de 2003 en donde el Estado comienza a generar instancias de participación dirigidas a los jóvenes. Es a partir de esta apertura al juego político que las juventudes argentinas son parte de las decisiones y de las acciones de gobierno. Es a partir de este nuevo discurso, que los y las jóvenes comienzan a sentir la política como la herramienta de transformación de sus realidades. A medida que fueron pasando los años, la juventud se convirtió en un actor protagónico del desarrollo nacional, aportándole la mística y el compromiso que todo proyecto nacional y popular requiere (2011:6).

Como se puede notar, las relaciones entre juventud y participación son elaboradas aquí desde un nuevo punto de vista: no solamente los sectores juveniles movilizados producen nuevas concepciones acerca 
de las instituciones formales de la política, que - como dice el documento - pasan a ser integradas a los repertorios de lucha social, sino que además el Estado aparece como impulsor o promotor de la participación juvenil; aspecto en relación con el cual, como veremos, el impulso de políticas participativas reconoce más y nuevos matices.

El parecido de familia entre la narrativa histórica elaborada por colectivos militantes y algunas de las interpretaciones reproducidas en el documento se hace más contundente si observamos que participan en la elaboración del mismo referentes y militantes de agrupaciones juveniles kirchneristas, como Kolina, Peronismo 26 de Julio, La Cámpora, Abogados por la Justicia Social (AJUS), entre otras. Asimismo, varios de los funcionarios y trabajadores estatales vinculados con la confección del documento, como desarrollamos más adelante, se identifican a sí mismos como militantes. En efecto, uno de los interesantes conceptos que aporta este documento tiene que ver con la referencia al presente como una etapa sociohistórica particular en la cual el modelo de gestión y de implementación de políticas públicas debe promover la articulación de la «gestión militante con la política» (Op. cit., 7). Es llamativo el modo en que el uso de este tipo de expresiones, también propias del universo de los militantes que trabajan en la administración pública, aparece de modo entrelazado con términos como los ya presentados (participación, construcción de ciudadanía, entre otras) que remiten al uso que se hace de las mismas en los documentos y puntos de vista de los organismos internacionales de juventud. Lo interesante, entonces, es reconocer cómo ambos lenguajes se mezclan y articulan entre sí, mostrando la importancia del impulso de políticas integrales, a la vez que destacando el valor del compromiso militante para transformar el Estado. Poniendo énfasis en el valor de los jóvenes como actores estratégicos del desarrollo, a la vez que como sujeto político y en tanto cientos de miles de jóvenes en las calles militando. Finalmente, es interesante advertir la específica relación que se postula entre políticas públicas de juventud, el Estado y las juventudes políticas movilizadas. Concretamente, porque se abona una lectura del protagonismo juvenil en el kirchnerismo que es resultado de una manera de entender el Estado, como también del diseño de regulaciones socioestatales encaminadas a promover esa participación militante. 


\section{LAS POLÍTICAS PÚBLICAS PARTICIPATIVAS DESDE LOS ORGANISMOS SECTORIALES DE JUVENTUD}

La implementación de políticas participativas en la DINAJU —a nivel normativo y práctico - reconoce una suerte revitalización en el año 2007 cuando, como se muestra en el documento «Políticas sociales de juventud: Aprendizajes y desafíos» (2007) anteriormente analizado, se define con claridad el trabajo desde una dimensión participativa. Asimismo, este año es importante para entender el proceso descripto puesto que coincide con la creación de una experiencia participativa para el trabajo con las juventudes a nivel provincial, más concretamente, en el marco de la gestión de gobierno del Socialista Hermes Binner (2007-2011) en la Provincia de Santa Fe. Hacemos referencia a la conformación del Gabinete Joven en el marco de la Dirección Provincial de Políticas de Juventud (Ministerio de Innovación y Cultura).$^{20}$ Como lo muestra Balardini (2009), esta es una experiencia ciertamente innovadora en materia de gestión de las juventudes a nivel estatal, puesto que - pese a fallidas experiencias llevadas adelante durante los gobiernos de Raúl Alfonsín y Carlos Menem- es la primera experiencia que tiene como fin la coordinación de las políticas públicas de juventud y la puesta en valor de una perspectiva juvenil en el impulso de las políticas públicas. Así, la experiencia del Gabinete Joven resulta interesante debido a su carácter innovador en materia de promoción de la participación juvenil a nivel estatal. Aunque la misma se impulsa desde una gestión de gobierno provincial - y en el marco de un gobierno que no es afín a la gestión kirchnerista - nos permite reconocer una suerte de contexto de época en el cual la dimensión participativa comienza a ser (re)tematizada fuertemente.

Volviendo sobre la (re)incorporación de la dimensión participativa en el impulso de acciones desde los organismos nacionales, en el marco de la segunda reunión del CFJ en 2008 se crean las «Jornadas de Democracia Participativa y Políticas Públicas», línea orientada a la realización de encuentros provinciales de entre uno y tres días de duración en los

20 El Gabinete Joven constituye un espacio de articulación transversal entre las políticas públicas destinadas a jóvenes en la Provincia de Santa Fe. Se trata de un espacio integrado por dos jóvenes en representación de cada uno de los Ministerios y una Secretaría -que tiene rango de Ministerio- con el que se busca incluir o promover una perspectiva joven en la construcción de las políticas públicas provinciales. 
que se convocan organizaciones juveniles para debatir - en palabras del entonces Secretario Ejecutivo del CFJ- «qué proyecto de país queremos» (Miradas al Sur, 29/07/2010). Concretamente, se trata de impulsar la creación de espacios de discusión política, tal como son caracterizados por trabajadores y funcionarios, de los que participan diferentes colectivos y agrupaciones que debaten sobre las formas de participación juvenil, sobre la manera en que se ejerce la ciudadanía entre los jóvenes y sobre el sentido de la participación.

Ese mismo año se crea el Programa «Jóvenes Padre Mugica», impulsado por el Consejo de Coordinación de Políticas Sociales de la Presidencia de la Nación y coordinado por la DINAJU, cuyo objetivo principal es «promover el servicio solidario, el compromiso social y la participación de los y las jóvenes en la búsqueda del fortalecimiento del tejido social» (DINAJU, 2014). Además de las acciones desarrolladas, resulta central la recuperación de la figura del Padre Mugica para entender la configuración de la dimensión participativa, puesto que se trata de un padre vinculado al Movimiento de Sacerdotes para el Tercer Mundo cuya actividad religiosa tuvo lugar en una de las más importantes villas miseria de la Ciudad de Buenos Aires que es asesinado en 1974 en manos de la Alianza Anticomunista Argentina, conocida como Triple A. ${ }^{21}$ En esta política pública, el sacerdote es caracterizado como expresión de la «opción por los más humildes», el «compromiso social», la «preocupación por el prójimo», la «lucha contra el individualismo» y la búsqueda por construir «una sociedad más justa». Vemos así que un conjunto de características en torno a las cuales suele ser descripto el compromiso militante - como entrega a una causa justa - son oficializadas y consagradas como valores en el marco de la implementación de una política pública.

En el año 2009, se lanza Mutuales del Bicentenario, una acción orientada a promover concretamente la construcción organizativa, política y territorial de los jóvenes. Se trata de impulsar la creación de Mutuales, interpretadas como «una forma de organización asociativa que busca dar respuestas a las propuestas y necesidades de la comunidad. Es un nuevo ámbito de participación política de la juventud, que por medio de prácticas sociales propone la construcción de poder colectivo» (Memoria 2009, CFJ). Este modelo organizativo, ilustra la búsqueda por formalizar e institucionalizar colectivos de jóvenes que

21 El accionar de la Triple A anticipa la política represiva del gobierno de facto, que se inicia en 1976. 
desarrollan diferentes grupos de trabajo por medio de actividades de formación y, luego, la vinculación con una serie de capacitaciones para conformar formalmente dichos grupos en tanto Mutuales, las cuales son vistas como una forma de «reconstrucción de lo público y de la política» (Ibídem). Las Mutuales creadas en torno a esta línea, son diversas e involucran el impulso de actividades de asesoría, servicios educativos (como cursos y talleres de formación), actividades recreativas, proveedurías, servicios de turismo, entre otras.

En 2010, se implementa una línea de acción denominada «Argentina Soberana y Popular», que consiste en la realización de dos encuentros, a los que asisten un total de cuatro mil jóvenes pertenecientes a unas 100 organizaciones de 20 provincias argentinas. Según el testimonio del entonces Director Ejecutivo del CFJ, la organización de estas jornadas tiene como propósito «construir una agenda política propia, generacional», que fuera correlato institucional de la «irrupción política de la juventud». En esta línea de acción se puede observar no solamente la articulación con colectivos juveniles movilizados sino, además, que los integrantes de dichos colectivos son los principales destinatarios de los encuentros. Se reconoce así la participación de activistas de AJUS, La Cámpora, la Juventud Sindical, la Juventud de Obras Públicas, el Observatorio de Política Latinoamericana Noticias del Sur, entre otros. La masividad de los asistentes a los encuentros y la marcada presencia de representantes de algunas de las principales agrupaciones políticas juveniles hace que los propios funcionarios lean la implementación de esta línea como un hecho político. Vemos así cómo para los funcionarios el hecho de gestionar políticas públicas participativas no tiene que ver únicamente con poseer competencias técnicas en cuanto a la gestión, sino que la posibilidad de impulsarlas, su éxito político y su eficacia aparecen vinculados con la capacidad de movilizar un capital social y con ser reconocidos por parte de organizaciones sociales, políticas, gubernamentales y no gubernamentales. Un éxito político en la gestión redunda, además, en un reconocimiento militante, como se puede observar cuando ese mismo año el Director Ejecutivo del CJF es nombrado Secretario General de la agrupación política Kolina. ${ }^{22}$

22 La Corriente de Liberación Nacional (Kolina) es creada en 2010 por Alicia Kirchner, Ministra de Desarrollo Social y hermana del ex Primer mandatario Néstor Kirchner. 
En 2011, se lanza Organizarnos para Transformar desde la DINAJU, línea de acción cuyo objetivo principal es promover la participación y organización de los jóvenes en las instituciones de enseñanza, más concretamente, esta línea de acción busca acompañar o consolidar la creación de Centros de Estudiantes (CE) en las comunidades educativas. Se trata de talleres de los que participan estudiantes de nivel medio, convocados por medio de las instituciones provinciales o locales de juventud, por organizaciones juveniles, escuelas o Ministerios de Desarrollo Social y/o de Educación provinciales. ${ }^{23}$

La sintética y apretada revisión de las políticas hasta aquí mencionadas, aunque no recorre su totalidad, permite mostrar cómo se comienzan a implementar las políticas participativas en los espacios sectoriales de juventud a nivel nacional, a la vez que las maneras en que se configura la dimensión participativa. Se puede destacar, a modo de síntesis, que los sentidos de la participación reconocen fronteras claras y delimitadas: se trata de modos de participar formalizados, por medio de la creación de CE, organizaciones o Mutuales. Asimismo, se trata de modalidades organizativas en las cuales el vínculo con el Estado se configura como elemento central, ya sea porque ese vínculo constituye un hito fundacional en la conformación de los grupos - como en el caso de las Mutuales - o como modo de apoyo o impulso a la consolidación de los mismos - como en el caso de los CE- Asimismo, comparten el hecho de ser diseñadas y/o implementadas por trabajadores que en su gran mayoría forman parte de organizaciones juveniles sociales y políticas que reconocen su trabajo como parte de una práctica militante. Finalmente, podemos decir que el impulso de las políticas públicas se articula con organizaciones juveniles, que funcionan como correas de transmisión entre el Estado Nacional y los jóvenes destinatarios.

Es interesante mencionar, además, que la evaluación de la implementación de estas líneas se pone en juego de acuerdo con aquello que funcionarios y trabajadores postulan como una suerte de modelo exitoso de participación. Según la evaluación de las acciones impulsadas por la DINAJU que hace una ex coordinadora de la Dirección: «a varios jóvenes que participaron de esos encuentros (en relación con los realizados en el marco de Mutuales del Bicentenario) los ves postulándose para concejal en algún Municipio en alguna Provincia o

23 Para acceder a un análisis pormenorizado de esta política pública, véase Vázquez y Núñez (2013), Vázquez, Cozachcow y Liguori (2014) y Vázquez (2015). 
como Directores de Juventud o a cargo de áreas de juventud» (Entrevista realizada por la autora, 10/10/2013). El testimonio ilustra cómo - desde el punto de vista de los responsables de las políticas públicas- el ideal participativo trasciende el hecho de ser destinatario de las mismas y tiene que ver con movilizar el Estado, con socializarse en sus reglas de juego y convertirse en «uno de ellos». A la vez que el hecho de haber sido destinatario de las políticas participativas es considerado como un capital entre quienes pasan a integrarse a la propia gestión de las mismas.

En síntesis, las líneas mencionadas permiten reconocer que el término participación no aparece asociado meramente a poner en ejercicio el empoderamiento, control o de monitoreo cívico. El mismo es asociado, además, al impulso de acciones organizativas entre los jóvenes, a la identificación de temas y asuntos centrales para éstos y a la construcción por parte de las organizaciones juveniles militantes de vínculos específicos con el Estado, a nivel local, provincial o nacional.

\section{LAS POLÍTICAS PARTICIPATIVAS DE JUVENTUD Y LAS JUVENTUDES PARTICIPATIVAS EN LA POLÍTICA}

Los desplazamientos semánticos, conceptuales y prácticos que se reconocen esquemáticamente en el pasaje de la participación a secas a una forma de consagrar la militancia en relación con el trabajo en el Estado, con el diseño de políticas participativas o con la vinculación con éstas en calidad de destinatarios, se pueden analizar en un contexto sociopolítico más amplio en el seno del cual cobran una fisonomía particular.

A título ilustrativo, la elaboración del documento «Políticas sociales de juventud. Aprendizajes y desafíos» (2007) anteriormente citado, es coincidente con la creación del CFJ por una iniciativa del Poder Ejecutivo. Esta nueva institución, que funciona bajo la órbita de la DINAJU, reconoce como principal misión coordinar el trabajo interjurisdiccional de las políticas de juventud y fortalecer y ampliar la «participación de jóvenes y de organizaciones juveniles» (Ley N²6.227, 28/03/2007). En este mismo sentido, quien fuera su Secretario en el año 2010, sostiene que «nosotros tenemos el convencimiento de que los jóvenes quieren hacer política y quieren por distintos modos ser protagonistas. Lo que hacemos es brindar los canales y poner a disposición el Estado» (Lablunda, Programa Radial Piedra Libre 24/06/2010). 
Asimismo, es interesante destacar la presencia de un conjunto de reconocidos dirigentes de agrupaciones juveniles como máximos responsables de las áreas de juventud desde 2006 en adelante, ${ }^{24}$ como es el caso de la DINAJU, del CFJ cuando es creado y de la SSJ desde 2014. Se trata de dirigentes vinculados a la agrupación juvenil La Cámpora y a Kolina, como son los casos de Juan Cabandié, ${ }^{25}$ Andrés La Blunda, ${ }^{26}$ Mariana Gras, ${ }^{27}$ Laura Braiza, ${ }^{28}$ Facundo Tignanelli, ${ }^{29}$ entre otros.

Estos y otros dirigentes de agrupaciones juveniles fueron convocados entre los años 2007 y 2008 por parte del ex presidente de la Nación, Néstor Kirchner, para conformar un «espacio político de la juventud». Se llevaron adelante encuentros y reuniones con líderes de Necesidades Básicas Insatisfechas (NBI) agrupación de la Facultad de Derecho de la Universidad de Buenos Aires, liderada por Mariano Recalde $;{ }^{30}$ con Juventud Compromiso K, vinculada con el entonces

24 Hasta entonces la Dirección de Juventud a nivel Nacional está en manos de Mariano Cascallares, nombrado en el año 2002 durante el gobierno provisional de Eduardo Duhalde (2002-2003).

25 Integrante de la Mesa Nacional de Conducción de La Cámpora, ingresa a trabajar en la DINAJU convocado por la Ministra de Desarrollo Social en el año 2004. Entre 2006 y 2007, es Secretario ejecutivo del CFJ. El recorrido militante de Cabandié se orientó hacia la actividad legislativa, concretamente, se desempeñó como legislador de la Ciudad de Buenos Aires entre los años 2007 y 2013. En la actualidad es diputado nacional por la Ciudad de Buenos Aires, por la lista del FPV.

26 Secretario general de Kolina, se ha desempeñado en cargos de gestión desde el año 2003, primero en el Consejo de Coordinación de Políticas Sociales de la Presidencia de la Nación y, luego, en el Ministerio de Desarrollo Social de la Nación. Fue máxima autoridad del CFJ entre 2008 y 2010. Actualmente coordina el Instituto Nacional de Asociativismo y Economía Social del Ministerio de Desarrollo Social.

27 Dirigente de Kolina, Directora Nacional de Juventud entre 2006 y 2010 $\mathrm{y}$, desde entonces, presidenta del Consejo Nacional de las Mujeres (Jefatura de Gabinete de Ministros de la Nación).

28 Vinculada inicialmente con el grupo de militantes del que surge $\mathrm{La}$ Cámpora, durante su desempeño como Directora Nacional de Juventud (entre 2010 y 2014) pasa a ser parte de Kolina.

29 Responsable político de La Cámpora en el distrito de La Matanza y Secretario de Organización de la Provincia de Buenos Aires, se desempeña desde 2014 como Subsecretario Nacional de Juventud.

30 Actual integrante de la Mesa Nacional de Conducción de La Cámpora y gerente de la reestatizada compañía aérea Aerolíneas Argentinas. 
Director de Juventud de la Provincia de Buenos Aires, José Ottavis; ${ }^{31}$ con la agrupación H.I.J.O.S ${ }^{32}$ de la que participaba Wado De Pedro ${ }^{33}$ y con Juventud Presente, impulsada por Andrés Larroque. ${ }^{34}$ Actividades de las que participaban también Juan Cabandié y Andrés Lablunda, entonces sin inscripción orgánica en las referidas agrupaciones pero posteriormente líderes en dos de las más importantes. Así como también Mariana Gras, quien entonces se desempeñaba como Directora Nacional de Juventud.

En los años 2008 y 2010 se producen dos hechos importantes para comprender la movilización de adhesiones militantes juveniles en espacios afines al kirchnerismo. En el año 2008, se crea la Resolución No.125 del Ministerio de Economía y Producción de la Nación, por medio de la cual se intenta aumentar el porcentaje de las retenciones a las exportaciones de soja y girasol, la cual produjo un intenso conflicto que llevó a grandes productores agropecuarios a sostener durante 129 días cortes de rutas y límites a la comercialización de granos y carnes, provocando restricciones al abastecimiento para el consumo. Las posiciones se fueron polarizando entre quienes apoyaban al gobierno, dados los ingresos extraordinarios de los grandes productores, y quienes apoyaban al campo, argumentado que el monto fijado resultaba excesivamente elevado. La participación de las agrupaciones políticas juveniles, sobre todo de La Cámpora y la Juventud Peronista Evita (JP Evita), crecen fuertemente en dicho contexto, al calor de acciones de apoyo al gobierno y a esta medida en particular. Pese a que el conflicto imposibilitó sancionar la referida Ley y frente a un escenario político en el cual el gobierno de Cristina Fernández consolidó fervientes oposiciones - algunas también militantes-, los todavía incipientes espacios juveniles del kirchnerismo se afianzaron y sembraron nuevos activistas.

El hito más significativo desde la perspectiva de los propios activistas, y desde los efectos concretos sobre la militancia en espacios

31 Actual integrante de la Mesa Nacional de Conducción de La Cámpora, Diputado de la Provincia de Buenos Aires por el Frente para la Victoria (FPV) y Vicepresidente de la misma Cámara.

32 Hijos por la Identidad y la Justicia contra el Olvido y el Silencio, organismo de Derechos Humanos creado a mediados de la década del 90.

33 Dirigente de La Cámpora, fue Diputado Nacional por el FPV y actualmente es Secretario General de la Presidencia.

34 Secretario General de La Cámpora y Diputado Nacional por el Frente para la Victoria. 
juveniles, es la muerte de Néstor Kirchner el 27 de octubre de 2010, en cuyos funerales se visibiliza una marcada movilización juvenil de apoyo al kirchnerismo, a la vez que durante los días sucesivos las agrupaciones reconocen un fuerte crecimiento de sus activistas. Cabe destacar que días antes de su muerte las principales organizaciones juveniles kirchneristas ${ }^{35}$ organizan un acto con el propósito de convocar a jóvenes y militantes de las diferentes agrupaciones juveniles a crear un «espacio político generacional de apoyo al modelo nacional y popular».

La descripción anterior permite reconocer, en primer lugar, un contexto político más amplio en el seno del cual la participación juvenil se convierte en un tema de agenda y se configura como categoría y actor central de la movilización política. Aunque el activismo juvenil no es propiedad exclusiva del kirchnerismo — son múltiples y heterogéneos los colectivos movilizados y los perfiles ideológicos de estos grupos-, resulta llamativo el modo en que desde este espacio político - que tampoco es uniforme y reconoce grupos de diferente trayectoria y posicionamiento político ideológico-, se consagra y oficializa una juventud como juventud militante. Asimismo, se construye una forma de participación específica en defensa o a favor de (el gobierno, propuestas de ley, acciones impulsadas desde el Estado, etcétera) y no en oposición o en contra de. El Estado, además, es integrado al universo de acciones militantes y pasa a ser leído como uno de los escenarios del compromiso militante. La denominada gestión militante designa el modo en que trabajadores que son militantes y los militantes que son trabajadores del Estado postulan relaciones y trazan puentes entre una forma de trabajar (con compromiso, muchas horas, por lo que menos tienen) y una forma de entender la militancia, que no solamente es por, para sino además desde el Estado (Vázquez, 2015). ${ }^{36}$

35 Entre las agrupaciones convocantes figuran La Cámpora, la Juventud Peronista de la Provincia de Buenos Aires, la Juventud Sindical —entonces alineada con el gobierno-, la Juventud Peronista Descamisados, el Movimiento Unidad Popular, Peronismo Militante, la Agrupación Martín Fierro y la Juventud Peronista Evita.

36 Pese a que estas configuraciones de sentido remiten centralmente a la coyuntura descripta, resulta ineludible hacer mención a dos momentos previos en los que también se observa una articulación entre la militancia juvenil y el trabajo en el Estado. En primer lugar, durante el breve gobierno de Héctor Cámpora (mayo-julio 1973), en el que se integran militantes pertenecientes a la Juventud Peronista (JP). Un caso ilustrati- 
Es interesante reconocer cómo estas configuraciones del sentido de la militancia en relación con el Estado, se observan particularmente en ciertas áreas - como las ya mencionadas de juventud a nivel nacional-y se articulan con el impulso de regulaciones socioestatales participativas, como las ya descriptas. Desde esta perspectiva podemos ver no solamente cómo los activistas postulan relaciones entre trabajo y militancia en la llamada gestión militante, sino que además la participación y la militancia se convierten en objetivos a alcanzar por medio de la implementación de las políticas públicas (participativas). Así, desde el Estado se produce y consagra oficialmente la juventud como una juventud movilizada cuyos efectos resultan performativos.

Esto mismo hace comprensible cómo y por qué algunas agrupaciones militantes pasarán a dar algunas de sus batallas políticas en el seno de la gestión pública, centralmente en áreas consideradas valiosas en su doble condición de trabajadores y militantes. Así como también algunas políticas públicas pasarán a estar vinculadas o asociadas con la labor militante de esos grupos.

\section{8. ¿QUÉ ES PARTICIPAR? HORIZONTES Y DISPUTAS DE SENTIDO}

Luego de mostrar el modo en que desde la gestión pública en el Estado se configuran condiciones de posibilidad para la reinterpretación en clave militante del trabajo en el Estado, así como el modo en que desde el activo militante afín al kirchnerismo el Estado se convierte en un espacio a movilizar - desde, para o por- el impulso de acciones militantes, resulta central incluir otros elementos al análisis. Más allá de las normativas y de la implementación de algunas de las políticas participativas aquí descriptas, en el despliegue de acciones y actores involucrados, la participación está lejos de reconocer un sentido unívoco. Como se ilustra a continuación, el impulso de políticas participativas abre un amplio abanico de sentidos y disputas por la defini-

vo es el de Dante Gullo, uno de los más destacados dirigentes de la JP, quien pasa a ser asesor de Asuntos de Juventud de la Presidencia de la Nación. En segundo lugar, durante el primer gobierno constitucional luego de la última dictadura militar, el gobierno de Raúl Alfonsín (1983-1989), también se consagra en la función pública a militantes y dirigentes provenientes de la organización juvenil vinculada a la Unión Cívica Radical: la Junta Coordinadora Nacional. 
ción legítima de qué es participar. Las reflexiones a continuación recogen resultados del trabajo de campo realizado en los organismos de juventud dentro del Ministerio de Desarrollo Social de la Nación.

Desde el punto de vista de los funcionarios, gestores y trabajadores involucrados en el impulso de las políticas participativas se reconocen diferentes posiciones que van desde la reivindicación militante del trabajo en el Estado en torno a regulaciones que buscan acompañar la participación y la organización de las juventudes, hasta la impugnación de estas acciones por ver en aquellas intentos de apropiación de los recursos y dispositivos del Estado por parte de algunas pocas agrupaciones. Entre estas posiciones extremas reconocemos otras que permiten establecer matices en las valoraciones, como es el caso de aquellos trabajadores de la gestión pública que, incluso cuando son activistas y asumen su doble condición de trabajadores y militantes en el Estado como un valor, realizan críticas hacia un modelo de militancia centralmente desde el Estado. Por un lado, apelando a concepciones más territoriales de la militancia, que reconocen el trabajo en los barrios populares como el corazón del quehacer militante. ${ }^{37}$ Por otro lado, las articulaciones entre militancia y trabajo son puestas en tensión a partir de su reconocimiento como trabajadores. Entre estos activistas se desarrolla un punto de vista que también es militante aunque, en este caso, vinculado con el punto de vista del espacio sindical en el que varios de los trabajadores del área están nucleados: el sindicato Unión Personal Civil de la Nación (UPCN). Aun cuando, como sostienen los propios trabajadores y funcionarios, se trata de un sindicato compañero - es decir, que acompaña la gestión de gobierno- - uno de los temas debatidos y discutidos es precisamente el de la gestión militante, en relación con la cual el sindicato identifica algunas tensiones relativas a su rol como defensor de los derechos de los trabajadores en el Estado y la reivindicación de una manera de trabajar (militante, comprometida) que exige una entrega al trabajo que va más allá de los horarios y días estipulados. Vemos así que en el espacio

37 Estos activistas suelen formular lecturas acusatorias hacia la llamada gestión militante, concretamente porque son militantes (centralmente barriales) que descalifican a la primera como una militancia de escritorio o porque ponen reparos frente a lo que se configura como un riesgo para la militancia: «convertirse en un burócrata o tecnócrata que se olvida de los problemas del barrio» (entrevista a trabajador de la DINAJU realizada por la autora, 26/09/2013). 
institucional de trabajo con las juventudes desde una mirada participativa y militante, aparecen tensiones en torno a la figura del trabajador militante, que es objeto tanto de reivindicaciones como de debates, disputas e impugnaciones.

La participación reconoce, además, heterogéneos sentidos desde el punto de vista de los destinatarios de las políticas públicas participativas. Esta cuestión se desprende, por ejemplo, del estudio en profundidad de la implementación de «Organizarnos para Transformar», línea de trabajo orientada a acompañar a los estudiantes de nivel medio a crear o consolidar Centros de Estudiantes en sus respectivas instituciones educativas. ${ }^{38}$ Tal como mostramos en trabajos anteriores (Vázquez, Cozachcow y Liguori, 2014; Vázquez, 2015), aun cuando se observa una presencia mayoritaria de estudiantes que impulsan actividades en sus escuelas - dentro y fuera de los CE- que se vinculan con los organismos de juventud a partir de la asistencia a este tipo de actividades y que se interesan por ser parte de la construcción de agendas locales, provinciales o nacionales de juventud, el modo en que se autodefinen varía ostensiblemente entre aquellos que leen la participación como una participación meramente estudiantil —acotada en tiempo y espacio al ámbito escolar - y aquellos otros que la ponen en relación de continuidad con una práctica militante más amplia.

Otra de las maneras en que la participación es puesta en tensión, se observa entre quienes asumen diferentes posiciones y valoraciones frente al hecho de que sea el Estado aquel que les ofrezca saberes y recursos para organizar CE. Dichas tensiones se solapan, en parte, con las anteriormente mencionadas en torno a la definición y los alcances de la participación. Concretamente porque son los y las jóvenes que se reconocen como militantes aquellos que en algunos de los talleres han interpelado directamente a los trabajadores y funcionarios acerca del por qué debe ser el Estado el que forme o acompañe la creación de los CE. ${ }^{39}$

38 Véase el apartado IV.

39 Esta lectura es confluyente con la interpretación que hace Núñez (2013) acerca del sentido que poseen los ce dentro de la tradición escolar. Según el autor, se trata del modo en el cual «se espera» que los estudiantes participen en la escuela secundaria. Desde este punto de vista, la promoción de la creación y/o participación en los CE aparece en un nuevo sentido, esto es, como una suerte de definición normativa sobre el sentido legítimo de la participación de los estudiantes dentro de la escuela y de acuerdo con parámetros adultocéntricos. 
Finalmente, entre agrupaciones juveniles militantes participar también es objeto de controversias. Las mismas se ponen de manifiesto entre aquellos colectivos alineados con la gestión de gobierno de Cristina Kirchner que resignifican la dimensión militante en relación con el Estado y aquellas otras agrupaciones que se reconocen como opositoras e impugnan la realización de acciones y regulaciones, tales como el impulso de políticas participativas. Estas últimas son vistas como un intento por monopolizar el sentido de las juventudes participativas y militantes.

\section{CONSIDERACIONES FINALES}

El presente artículo intenta mostrar los heterogéneos sentidos que se anudan en el diseño e implementación de las políticas participativas de juventud en Argentina. Estas pueden leerse en relación de continuidad con una serie de regulaciones estatales de tipo participativo, en general, que cobran vigor desde mediados de la década del '90 y, más centralmente, con posterioridad a la crisis de representación política del año 2001 en Argentina que se nutren de lineamientos desarrollados desde diferentes organismos internacionales, pero también deben ser interpretadas en función de las condiciones locales de recepción, interpretación y producción de la cuestión juvenil y participativa. Así, se muestran cuáles son las políticas participativas, qué peso tienen frente a otras y las áreas institucionales y funcionarios de las que dependen. Se pone atención, además, en los organismos sectoriales de juventud a nivel nacional, de los cuales dependen centralmente, y en relación con los cuales se configura un espacio de inserción militante para jóvenes activistas que ven en dichas áreas y en aquellas políticas una suerte de ampliación de su repertorio de acciones militantes.

Así, el trabajo nos habla sobre una cuestión central e, incluso, singular del caso argentino, esto es: la centralidad de cuestión participativa de los grupos juveniles en un contexto específico en el cual la condición juvenil es reivindicada. Se muestra, sin embargo, que el sentido de la participación es multiforme y se convierte en objeto de disputas entre grupos y colectivos.

Ahora bien, el artículo también nos habla de los organismos de juventud y las acciones impulsadas. Mostrando los recorridos, ambivalencias, herencias, relecturas y tensiones en las que se reconoce la producción socioestatal de las juventudes desde una clave participati$v a$. Por un lado, explorando interesantes confluencias entre organis- 
mos internacionales, el Estado nacional y — más precisamente - áreas específicas dentro de aquél, expertos y organizaciones políticas que imprimen distintos énfasis y sentidos a las políticas públicas participativas destinadas a las juventudes. Reunir y poner en común elementos sin evidente articulación a priori, facilita abordarlas de modo complejo, atendiendo a sus condiciones sociológicas de posibilidad, historizando y reconstruyendo el sentido de las dinámicas institucionales, desentrañando las lógicas de trabajo, los perfiles y capitales que favorecen el ingreso y la permanencia de trabajadores y funcionarios de la gestión pública, detectando el uso y recreación de términos y categorías que se configuran en la implementación de regulaciones socioestatales, así como los puntos de encuentro y desencuentro entre los procesos de movilización, el Estado y las juventudes.

Por otro lado, el artículo muestra que la impronta participativa se reconoce centralmente en acciones que no llegan a ser definidas en términos programáticos, que poseen complejas condiciones de continuidad en el tiempo y que están fuertemente supeditadas a cambios de gestiones y tensiones internas que las restringen en sus propios fines. De acuerdo con esto, se muestra que la dimensión participativa, lejos de ser un elemento transversal, presente en las diferentes políticas públicas y producciones socioestatales, permanece acotada en acciones desarrolladas por organismos específicos de juventud cuyos vínculos otros organismos estatales igual o más involucrados con el impulso de políticas públicas destinadas a las juventudes son limitados. Así, las políticas de mayor impacto, presupuesto y continuidad en el tiempo, dependen de Ministerios y dependencias estatales (como el ANSES) en los que no se trabaja ni con un enfoque participativo, ni con un enfoque de juventud propiamente dicho. Encarando el trabajo con las juventudes con base en la delimitación de franjas etarias o la construcción de grupos de edad.

En función de los puntos mencionados, el trabajo presenta una interesante paradoja en la configuración actual de las juventudes en Argentina, de acuerdo con la cual se reconoce tanto impronta de la cuestión juvenil en materia de movilización y organización colectiva de las juventudes -incluso entre aquellos grupos oficialistas en los cuales algunos activistas trabajan en el Estado- como también la relativa ausencia de políticas públicas de juventud que atiendan de modo sostenido en el tiempo las principales cuestiones relativas a las experiencias juveniles. 
La impronta pública y política de las juventudes en el contexto local actual también se presenta de modo paradojal al reconocer la inexistencia de encuestas de juventud que permita conocer mejor quiénes son los y las jóvenes, así como también de una Ley de Juventud que establezca y defina un piso de acciones a desarrollar. Esto no solo resulta paradojal sino además contrastante con otros países de América Latina que - sin contar con juventudes políticas con tanta visibilidad pública - han dado lugar igualmente a este tipo de regulaciones socioestatales.

BUENOS AIRES (ARGENTINA), FEBRERO 2015

RECIBIDO: FEBRERO 2015 ACEPTADO: JULIO 2015

\section{REFERENCIAS BIBLIOGRÁFICAS}

Aguilar, Paula, Sabina Dimarco, Ana Grondona y Sol Montero (2006): «El plano subjetivo en la estrategia de lucha contra la pobreza del Banco Mundial». En MANUEl ANGEL RODRÍGUEZ y JORGE PRÓSPERO ROZE (compiladores): Ciudades latinoamericanas III: Transformaciones, identidades y conflictos urbanos en los albores del siglo XXI. México/Argentina: Colección Memoria/Fundación Ideas.

ANNUZIATA, Rocío (2013): «Una propuesta de clasificación de los dispositivos participativos en Argentina». POSTdata. Revista de reflexión y análisis político, Vol. 18, $\mathrm{N}^{\circ} 2$.

BALARDINI, SERGIO (1999): «Políticas de juventud: conceptos y la experiencia argentina». Última Década $\mathrm{N}^{\circ} 10$. Valparaíso: Ediciones CIDPA. (2009): El Gabinete Joven. Una política innovadora del Gobierno de Santa Fe. Buenos Aires: FES.

(2004): «Políticas de juventud en Argentina. Balance y perspectivas». En Elizabeth Gerber y Sergio Balardini (compiladores): Políticas de juventud en Latinoamérica. Argentina en perspectiva. Buenos Aires: FLACSO/EBERT.

- (2000): «Prólogo». En SERGIO BALARDINI (compilador): La participación social y política de los jóvenes en el horizonte del nuevo siglo. Buenos Aires: CLACSO.

(1999): «Políticas de juventud: conceptos y la experiencia argentina». Última Década $\mathrm{N}^{\circ} 10$. Valparaíso: Ediciones CIDPA.

Borzese, DANA, NATAlia Gianatell y Roberta RUiz (2006): «El papel del mercado según el discurso del Banco Mundial (1997-2004). Implicaciones en la visión del mercado, la sociedad y los sujetos». En 
MANuel ANGel RodríGueZ y JORGe PrósPero Roze (compiladores): Ciudades latinoamericanas III: Transformaciones, identidades y conflictos urbanos en los albores del siglo XXI. México/Argentina: Colección Memoria/Fundación Ideas.

DAGNINO, EVELINA (2006): «Sociedad civil, participación y ciudadanía, ¿de qué estamos hablando?». En E. ISUNZA VERA y A. OlVERA (coordinadores): Democratización, rendición de cuentas y sociedad civil: participación ciudadana y control social. México: Centro de Investigaciones y Estudios Superiores de Antropología, Universidad Veracruzana.

GONZÁlEZ, ALEJANDRA SOLEDAD (2014): «Las artes en la última dictadura argentina (1976-1983): entre políticas culturales e intersticios de resistencia». European Review of Artistic Studies, Vol. 5, №2.

ISUNZA VERA, ERNESTO y ALBERTO OlVERA (coordinadores) (2006): Democratización, rendición de cuentas y sociedad civil: participación ciudadana y control social. México: Centro de Investigaciones y Estudios Superiores de Antropología, Universidad Veracruzana.

LORENZ, FEDERICO (2006): Las guerras por Malvinas. Buenos Aires: Edhasa.

LANDAU, Matías (2008): Política y participación ciudadana en la Ciudad Autónoma de Buenos Aires. Buenos Aires: Miño y Dávila Editores.

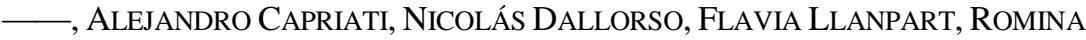
Malagamba Otegui, IVAna Socoloff, Agustina Pérez Rial (2006): «Interesados en la participación: un estudio sobre los discursos del Banco Mundial». En MANuEL ANGEL Rodríguez y JORGE PrósPero RozE (compiladores): Ciudades latinoamericanas III: Transformaciones, identidades y conflictos urbanos en los albores del siglo XXI. México/Argentina: Colección Memoria/Fundación Ideas.

LIGUORI, MARIANA (2006): «Políticas públicas de juventud y organismos sectoriales de juventud a nivel nacional: los años 80 y 90» (mimeo).

NÚÑEZ, PEDRO (2004): «Estrategias de participación de jóvenes en el AMBA: políticas públicas, culturas juveniles y ciudadanía en Argentina». Maestría en Estudios y Políticas de Juventud, UDL/UAB/URV/UDG (mimeo).

- (2013): La política en la escuela. Jóvenes, justicia y derechos en el espacio escolar. Buenos Aires: La Crujía Ediciones.

PÉREZ, GERMÁN y ANA NATALUCCI (compiladores) (2012): Vamos las bandas. Organizaciones y militancia kirchnerista, Buenos Aires: Nueva Trilce.

PLESNICAR, LORENA (2010): «El discurso de la OIJ sobre la participación de la juventud en el desarrollo (1980-2000)». Revue Interdisciplinaire des travaux sur les Amériques $\mathrm{N}^{\circ} 4$.

RESTREPO, DARIO (1997): «Eslabones y precipicios entre participación y democracia», ponencia presentada en la Comisión para la Reforma del Estado, Caracas 22-24 de septiembre.

ROFMAN, ADRIANA (2013): «La participación ciudadana entre la movilización y la institucionalización: una revisión de los estudios sobre partici- 
pación ciudadana local en la Argentina». Consultado el 22 de noviembre 2014. Disponible en línea: www.academia.edu.

(2007): «Participación de la sociedad civil en políticas públicas: una tipología de mecanismos institucionales participativos», ponencia presentada en la VI Conferencia Regional de ISTR para América Latina y el Caribe, Salvador de Bahía, Brasil, del 8 al 11 de noviembre, USTR y CIAGS/UFBA.

VÁZQUeZ, MELINA (2012): «Relato histórico y categorías de inscripción pública del compromiso: aproximaciones al liderazgo como práctica militante». Revista Trabajo y Sociedad $\mathrm{N}^{\circ} 19$. Universidad Nacional de Santiago del Estero.

(2013): «En torno a la construcción de la juventud como causa pública durante el kirchnerismo: principios de adhesión, participación y reconocimiento». Revista Argentina de Juventud, Universidad Nacional de La Plata, 1(7).

— (2015): Juventudes, Estado y participación en la Argentina actual: aproximaciones a la producción socioestatal de las juventudes desde las políticas públicas participativas, Buenos Aires: Grupo Editor Universitario.

—-, Alejandro CozachCow y Mariana Liguori (2014): «Estudiantes secundarios, Estado y participación política: una aproximación desde la implementación de políticas (participativas) de juventud», ponencia presentada en el XI Congreso Argentino de Antropología Social, Santa Fe.

— y PEDRO NúÑEZ (2012): «Políticas públicas de juventud e inclusión social en América Latina y el Caribe». CLACSO/UNESCO (mimeo).

— y PABLo Vommaro (2012): «Con la fuerza de la juventud: aproximaciones a la militancia kirchnerista desde La Cámpora». En GERMÁN PÉREZ y ANA NATALUCCI (compiladores) (2012): Vamos las bandas. Organizaciones y militancia kirchnerista, Buenos Aires: Nueva Trilce.

Wende ABRAMO, Helena (2004): «Políticas de juventud en Brasil. Nuevos tiempos, nuevas miradas». En ElizABETH GERBER y SERGIO BALARDINI (compiladores): Políticas de juventud en Latinoamérica. Argentina en perspectiva. Buenos Aires: FLACSO/FES. 


\section{ANEXO: LISTADO DE POLÍTICAS PÚBLICAS DE JUVENTUD RELEVADAS, POR DEPENDENCIA ESTATAL}

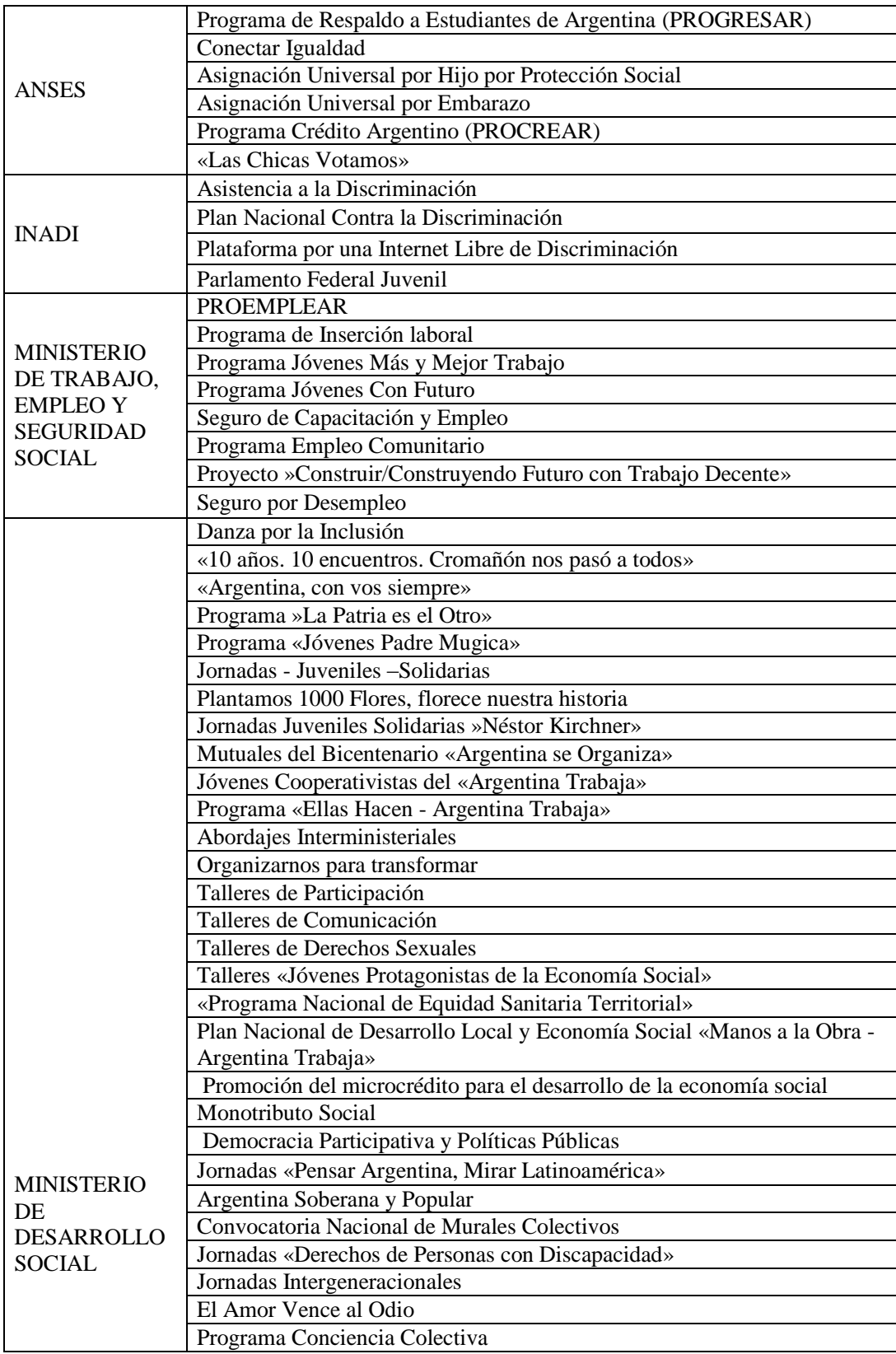




\begin{tabular}{|c|c|}
\hline & Soy Positivo \\
\hline & Foros por la Democratización Universitaria \\
\hline & Programa «Yo, Mamá» \\
\hline & Capacitaciones Padre Carlos Mugica \\
\hline & Plan Nacional de Acción por los Derechos de NN y A \\
\hline & Programa Nacional de Adolescentes «Nuestro Lugar» \\
\hline & Programa «Acá la Palabra» \\
\hline & Proyecto de «Líderes Comunicacionales» \\
\hline & Sinfonía Popular \\
\hline & Escuela MOST - UNESCO \\
\hline & Plan Nacional del Deporte Social \\
\hline & Becas Deportivas \\
\hline & Programa Social y Deportivo Juegos Nacionales Evita \\
\hline & Programa Nacional de Ligas Deportivas \\
\hline & Argentina, Nuestra Cancha \\
\hline \multirow{32}{*}{$\begin{array}{l}\text { MINISTERIO } \\
\text { DE } \\
\text { EDUCACION }\end{array}$} & $\begin{array}{l}\text { Encuentros Nacionales «Debatir para Transformar, transformar para } \\
\text { incluir» }\end{array}$ \\
\hline & Parlamento Juvenil del Mercosur \\
\hline & Programa Nacional de Educación Sexual Integral \\
\hline & Programa Integral para la Igualdad Educativa \\
\hline & Plan Nacional de Educación Obligatoria y Formación Docente \\
\hline & Plan Nacional de Educación Secundaria \\
\hline & Programa Nacional de Educación Solidaria \\
\hline & Programa Nacional de Inclusión Educativa «Todos a Estudiar» \\
\hline & Plan Nacional de Lectura \\
\hline & Programa Nacional de Convivencia Escolar \\
\hline & Red de Organizaciones Solidarias para el Derecho a la Educación \\
\hline & Portal del Estudiante \\
\hline & Plan de Finalización de Estudios Primarios y Secundarios - FiNes \\
\hline & Voluntariado Universitario \\
\hline & Programa Nacional de Becas Bicentenario \\
\hline & Programa Nacional de Becas Universitarias \\
\hline & Becas Escolares \\
\hline & Jornadas Deportivas Universitarias «Por. Néstor Kirchner» \\
\hline & La Universidad con YPF \\
\hline & La Universidad en los Barrios, los Barrios en la Universidad \\
\hline & Programa Nacional de Extensión Educativa «Abrir la Escuela» - CAJ \\
\hline & Mesas Socioeducativas para la Inclusión y la Igualdad \\
\hline & Proyecto de Prevención del Abandono Escolar \\
\hline & $\begin{array}{l}\text { Programa Federal Red de Aulas Talleres Móviles de la Educación Técnico } \\
\text { Profesional }\end{array}$ \\
\hline & Programa de Orquestas y Coros Infantiles y Juveniles para el Bicentenario \\
\hline & Programa de Educación para el Trabajo y la Integración Social \\
\hline & Programa «Elegir la Docencia» \\
\hline & Programa Nacional «Escuelas y Medios» \\
\hline & Programa Nacional de Educación en Contexto de Encierro \\
\hline & Programa Nacional de Organización Estudiantil de Centros de Estudiantes \\
\hline & Argentina Investiga \\
\hline & Universidad Diseño y Desarrollo Productivo \\
\hline
\end{tabular}




\begin{tabular}{|c|c|}
\hline \multirow{8}{*}{$\begin{array}{l}\text { MINISTERIO } \\
\text { DE CIENCIA, } \\
\text { TECNOLOGÍA } \\
\text { E } \\
\text { INVOCACIÓN } \\
\text { PRODUCTIVA }\end{array}$} & Becas TIC \\
\hline & Programa ANR EMPRESA JOVEN FONSOF \\
\hline & Red de Argentinos Investigadores y Científicos del Exterior \\
\hline & Becas CONICET \\
\hline & Becas Jóvenes Profesionales TIC C1/C2 \\
\hline & Concurso literario juvenil «La ciencia en los cuentos 2014» \\
\hline & Plan Nacional de Argentina Innovadora 2020 \\
\hline & INNOVAR \\
\hline \multirow{2}{*}{$\begin{array}{l}\text { MINISTERIO } \\
\text { DE CULTURA }\end{array}$} & Concurso Internacional de Ciencia Ficción Juvenil \\
\hline & Ajedrear \\
\hline \multirow{11}{*}{$\begin{array}{l}\text { MINISTERIO } \\
\text { DE SALUD }\end{array}$} & Plan Nacer - Seguro Nacional Materno Infantil \\
\hline & Programa Sumar \\
\hline & $\begin{array}{l}\text { Calendario de Vacunación - Programa Nacional de Enfermedades Inmu- } \\
\text { nopreventivas }\end{array}$ \\
\hline & $\begin{array}{l}\text { Programa de Abordaje Territorial Sanitario // Programa Nacional de } \\
\text { Equidad Sanitaria Territorial - Unidades Sanitarias Móviles». }\end{array}$ \\
\hline & Programa Nacional de Salud Sexual y Procreación Responsable \\
\hline & Programa Cuidarse en Salud \\
\hline & Portal «Vamos a Crecer» \\
\hline & Programa Nacional de Salud Integral para el Adolescente \\
\hline & Plan Nacional de Salud Mental \\
\hline & $\begin{array}{l}\text { Programa Nacional de } \\
\text { Lucha Contra los Retrovirus Humanos, SIDA } \\
\text { y Enfermedades de Transmisión Sexual }\end{array}$ \\
\hline & HPV - Todos por mañana \\
\hline \multirow{4}{*}{$\begin{array}{l}\text { MINISTERIO } \\
\text { DE } \\
\text { PLANIFICACIÓ } \\
\text { N FEDERAL, } \\
\text { INVERSIÓN } \\
\text { PÚBLICA Y } \\
\text { SERVICIOS }\end{array}$} & Programa Nacional 700 Escuelas, Mas Escuelas \\
\hline & Programa Federal de Construcción de Vivienda - Techo Digno \\
\hline & Programa de Mejoramiento Habitacional e Infraestructura - PROMHIB \\
\hline & Banco Audiovisual de Contenidos Universales Argentinos - BACUA \\
\hline \multirow{7}{*}{$\begin{array}{l}\text { MINISTERIO } \\
\text { DE INDUSTRIA }\end{array}$} & PROCREAUTO \\
\hline & Plan Estratégico Industrial 2020 \\
\hline & Aprendiendo a Emprender \\
\hline & Programa de Desarrollo Emprendedor - Capital Semilla \\
\hline & Programa MI PC \\
\hline & Programa MI PC Móvil \\
\hline & Empresas Madrinas \\
\hline $\begin{array}{l}\text { MINISTERIO } \\
\text { DE ECONOMÍA } \\
\text { Y FINANZAS } \\
\text { PÚBLICAS }\end{array}$ & Programa Impulsores de tu país, para vos \\
\hline $\begin{array}{l}\text { MINISTERIO } \\
\text { DE } \\
\text { AGRICULTUR } \\
\text { A, } \\
\text { GANADERÍA Y } \\
\text { PESCA }\end{array}$ & Jóvenes Emprendedores Rurales \\
\hline
\end{tabular}




\begin{tabular}{|c|c|}
\hline \multirow{3}{*}{$\begin{array}{l}\text { MINISTERIO } \\
\text { DEL INTERIOR } \\
\text { Y } \\
\text { TRANSPORTE }\end{array}$} & Programa de Fortalecimiento de la Seguridad Vial \\
\hline & Taller Itinerantes \\
\hline & Plan Nacional de Formación Política \\
\hline \multirow{4}{*}{$\begin{array}{l}\text { MINISTERIO } \\
\text { DE JUSTICIA Y } \\
\text { DERECHOS } \\
\text { HUMANOS } \\
\end{array}$} & Plan Nacional de Prevención del Delito \\
\hline & Programa Comunidades Vulnerables \\
\hline & Programa Nacional con Vos en la Web \\
\hline & Registro de Información de Personas Menores Extraviadas \\
\hline \multirow{2}{*}{$\begin{array}{l}\text { MINISTERIO } \\
\text { DE } \\
\text { SEGURIDAD } \\
\end{array}$} & Plan de Participación Comunitaria - Mesas de Participación Ciudadana \\
\hline & Escuela de Cadetes - Ingreso a la Policía Federal Argentina \\
\hline $\begin{array}{l}\text { MINISTERIO } \\
\text { DE DEFENSA }\end{array}$ & Incorporación al Ejército Argentino \\
\hline \multirow{10}{*}{$\begin{array}{l}\text { JEFATURA DE } \\
\text { GABINETE DE } \\
\text { MINISTROS }\end{array}$} & Programa «El Héroe Colectivo» \\
\hline & Becas de Formación en el Exterior en Ciencia y Tecnología - BE.CAR \\
\hline & Programa Jóvenes por un Ambiente Sustentable \\
\hline & Programa Memoria en Movimiento, Comunicación y DDHH \\
\hline & Concurso «Argentina Comparte Historias de Compromiso» \\
\hline & Concurso «Cuentos Cortos» - La Historia la Ganan los que escriben \\
\hline & Maravillosa Música \\
\hline & Portal «Argentina Comparte» \\
\hline & Programa Nacional Consejos Deliberantes Estudiantiles \\
\hline & Talleres En tus manos + democracia \\
\hline \multirow{8}{*}{$\begin{array}{l}\text { PRESIDENCIA } \\
\text { DE LA NACIÓN }\end{array}$} & Programa Social de Orquestas y Bandas Infantiles y Juveniles \\
\hline & Programa «Prevención y Participación Juvenil» \\
\hline & Programa de Prevención en el ámbito educativo «Quiero Ser» \\
\hline & Programa Recuperar Inclusión \\
\hline & $\begin{array}{l}\text { Programa de Fortalecimiento de Derechos y Participación de las Mujeres } \\
\text { «Juana Azurduy» }\end{array}$ \\
\hline & Plan Nacional de Abordaje Integral - Ahí en el Lugar \\
\hline & Argentina, el verano de un amor. Más la conoces, más la querés. \\
\hline & Sistema Único de Prestaciones Básicas para Personas con Discapacidad \\
\hline
\end{tabular}

